Old Dominion University

ODU Digital Commons

Fall 2015

\title{
The Effects of Task Criticality and Target Modality on a Simulated Battlefield Search Task
}

Julie A. Hanson

Old Dominion University, jewelshanson@gmail.com

Follow this and additional works at: https://digitalcommons.odu.edu/psychology_etds

Part of the Quantitative Psychology Commons

\section{Recommended Citation}

Hanson, Julie A.. "The Effects of Task Criticality and Target Modality on a Simulated Battlefield Search Task" (2015). Master of Science (MS), Thesis, Psychology, Old Dominion University, DOI: 10.25777/ brje-0764

https://digitalcommons.odu.edu/psychology_etds/14

This Thesis is brought to you for free and open access by the Psychology at ODU Digital Commons. It has been accepted for inclusion in Psychology Theses \& Dissertations by an authorized administrator of ODU Digital Commons. For more information, please contact digitalcommons@odu.edu. 


\title{
THE EFFECTS OF TASK CRITICALITY AND TARGET
}

\section{MODALITY ON A SIMULATED BATTLEFIELD SEARCH TASK}

\author{
by
}

\author{
Julie A. Hanson \\ B.S. May 2012, Old Dominion University \\ A Thesis Submitted to the Faculty of \\ Old Dominion University in Partial Fulfillment of the \\ Requirements for the Degree of \\ MASTER OF SCIENCE \\ PSYCHOLOGY \\ OLD DOMINION UNIVERSITY \\ December 2015
}

Approved by:

James P. Bliss (Director)

John C. Brill (Member)

Cathy Lau-Barraco (Member) 


\section{ABSTRACT \\ THE EFFECTS OF TASK CRITICALITY AND TARGET MODALITY ON A SIMULATED BATTLEFIELD SEARCH TASK \\ Julie A. Hanson \\ Old Dominion University, 2015 \\ Director: James P. Bliss}

Warfighters must rely on lengthy instruction manuals when asked to perform tasks in critical environments. These instruction manuals are predominantly written in text and rarely include images. Several theoretical frameworks, including the Pictorial Superiority Effect, posit images to be more effective forms of instruction for short-term memory recall tasks. It is unclear whether pictures are superior forms of instruction for use in tasks with potential life-threatening consequences. Recently, studies have attempted to define and manipulate task criticality to determine the effects a critical scenario may have on operator performance. Findings have been equivocal, perhaps because of the ambiguity associated with the definition of task criticality. The purpose of the current work was to determine whether images or textual descriptions were more effective forms of instruction for a target search task in a critical scenario (defined as a task with life-threatening consequences). Forty participants were asked to participate in this study. Twenty participants had military deployment experience and twenty participants were students with no deployment experience. Participants were asked to traverse a virtual battlefield environment to search for targets; half of which were presented with images and the other half with textual descriptions. Participants searched for targets under conditions of both low and high task criticality. This study used a $2 \times 2$ $\times 2$ quasi-experimental mixed design and results were analyzed using a series of mixed 
ANOVAs. The results showed both samples collected more pictorial targets in the high criticality condition than in the low criticality condition. Participants collected pictorial targets faster than lexical targets, and military participants took longer to locate textual targets in the high criticality condition. Military personnel and students made more errors searching for lexical targets, and military overall made more errors than students in both conditions. Military participants experienced higher cognitive workload in the high criticality condition. These results lend credence to the Pictorial Superiority Effect, DualCoding Theory, and the Critical Decision Method. As pictorial information may lower cognitive resource demand, these results suggest that warfighters and other operators should be presented with pictorial information during a critical task to increase performance and minimize errors. 
Copyright, 2015, by Julie A. Hanson and Old Dominion University, All Rights Reserved. 
This thesis is dedicated to my family and friends who supported me through graduate school (special thanks to William Brock Jr. for your unwavering support). This thesis is also dedicated to all of the members of the US Armed Forces that spend their days protecting the rights and freedoms of the American people. One member, specifically, made this thesis possible. Thank you. 


\section{ACKNOWLEDGMENTS}

I would like to acknowledge my friends, family, and the wonderful people in the ODU Psychology Department that contributed to my academic voyage. I would like to thank my advisor, Dr. Jim Bliss, for his support and guidance during the most difficult

journey in my life (thus far). Special thanks to committee members Dr. Chris Brill and Dr. Lau-Baracco for their valuable insight and advice that has greatly improved the quality of the work presented here. Thank you to members of the R.E.A.C.T.S. lab for your unwavering support and all of your help; your friendship will never be forgotten. 
TABLE OF CONTENTS

Page

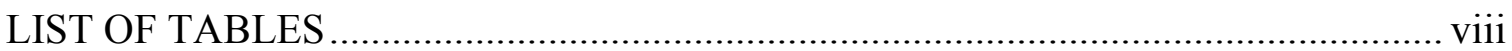

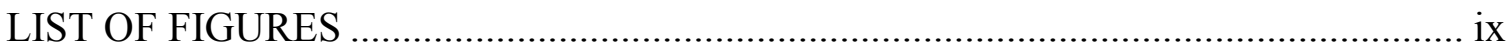

Chapter

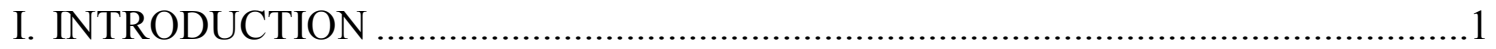

STATIC INSTRUCTIONAL MODALITY PARADIGM …….................................

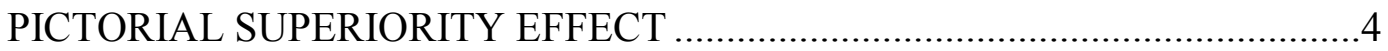

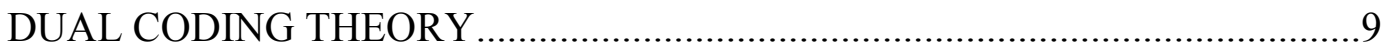

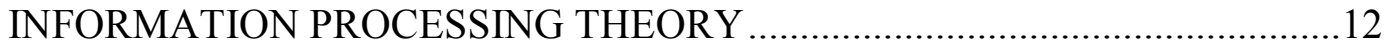

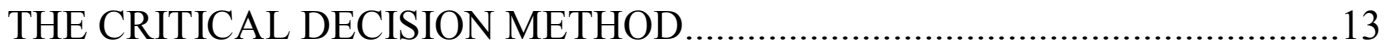

STRESS, PERFORMANCE, AND CRITICALITY ………..............................14

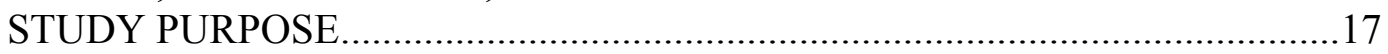

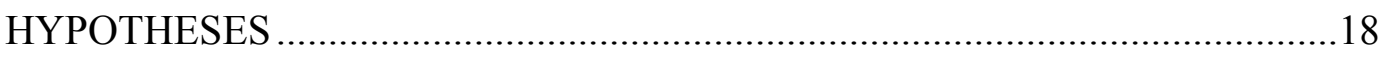

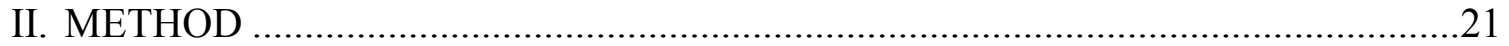

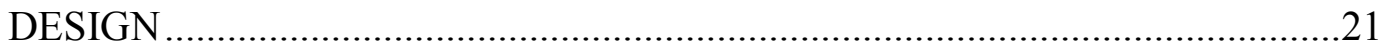

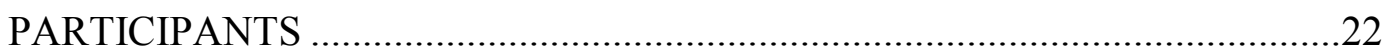

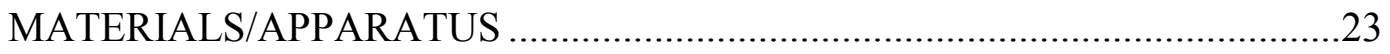

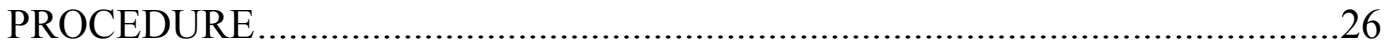

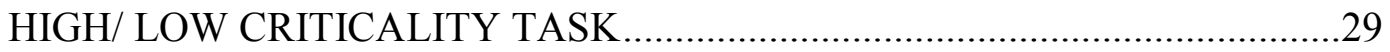

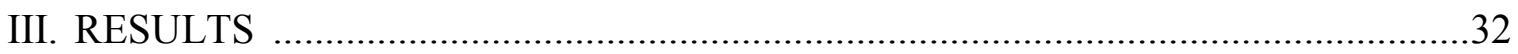

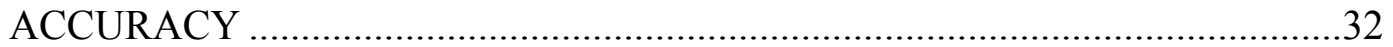

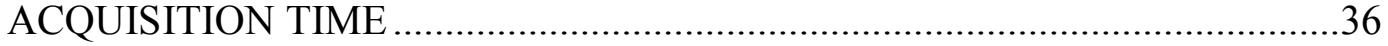

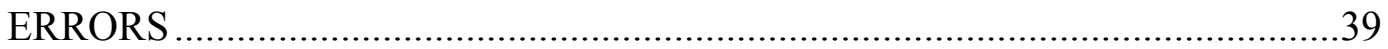

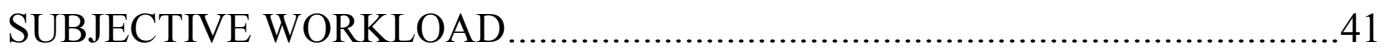

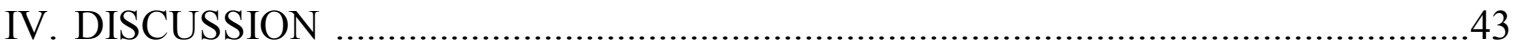

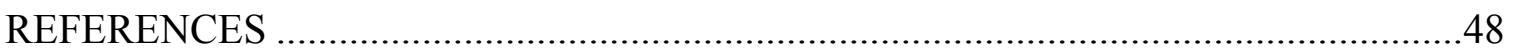

APPENDICES

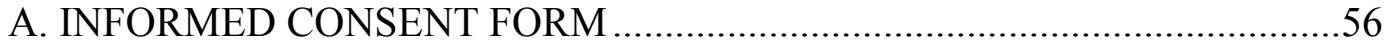

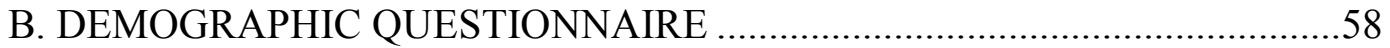

C. MILITARY BACKGROUND QUESTIONNAIRE ......................................59

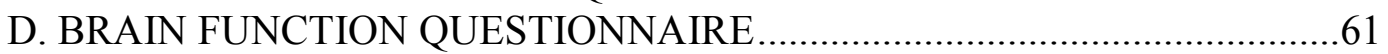

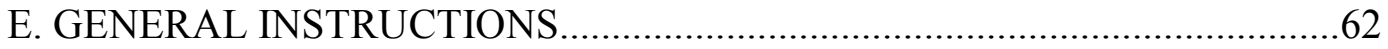

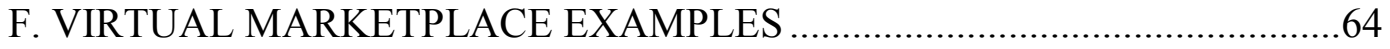

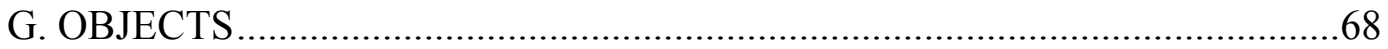


H. HIGH/ LOW CRITICALITY TASK INSTRUCTIONS ..................................72

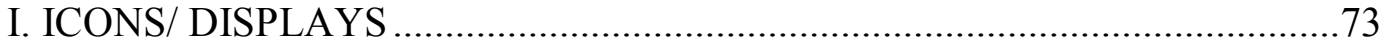

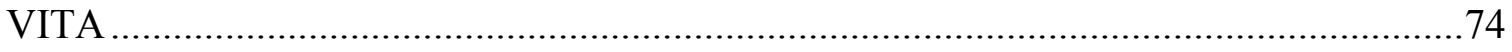




\section{LIST OF TABLES}

Table

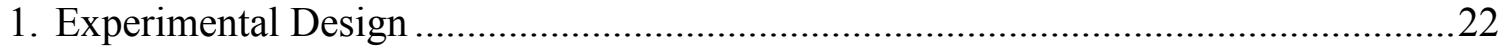

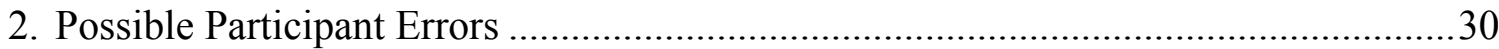

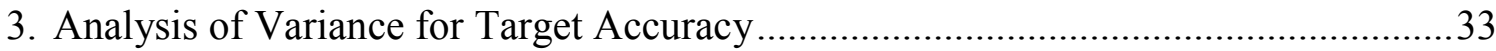

4. Means and Standard Deviations for Target Accuracy...........................................34

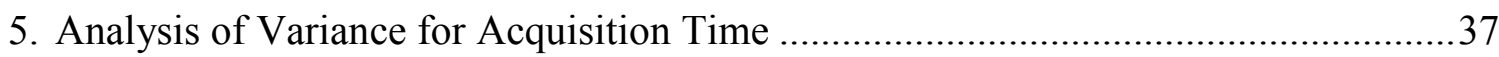

6. Means and Standard Deviations for Acquisition Time ......................................... 37

7. Analysis of Variance for Errors of Commission ............................................... 40 


\section{LIST OF FIGURES}

Figure

Page

1. Simplified Model of Text and Picture Integration

2. Target Retrieval Accuracy as a Function of Task Criticality, Information Modality, and Participant Background ...................................................35

3. Mean Target Location Rate as a Function of Information Modality,

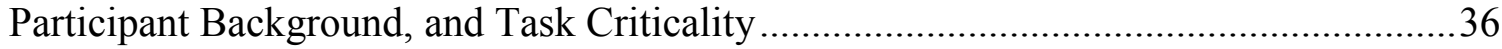

4. Target Acquisition Time for each Criticality Condition as a Function of Target Modality Presentation.

5. Cognitive Workload Means for each Subscale Relative to Population and Criticality Level 


\section{INTRODUCTION}

Training and the correct use of learned information is critical on the battlefield.

In the presence of danger, warfighters do not have time to peruse an instruction manual to ensure the correct steps are followed when faced with a critical task. Further, warfighters often do not have time to scan a lengthy document to search for pertinent information. It is imperative that a warfighter be provided with information in the most compelling, accurate, and clear modality of communication. Recent scientific literature has focused on the most useful communication modality for instruction concerning short term memory tasks, but literature is generally unavailable to guide the selection of instructional modality for critical scenarios. The focus of the current study is to determine whether images or text provide for more effective forms of instruction in a critical battlefield scenario.

Although warfighters may potentially have access to a field manual, it is more likely they will rely on the knowledge of fellow team members or "intelligence" information to complete a critical task or mission. As defined by the US Army, "intelligence" refers to the evaluation and integration of operations and hostile force information resulting in increased environmental understanding and situation awareness (Army Doctrine Reference Publication (ADRP) 2-0, 2012). Often intelligence is conveyed by audio communication (a Command and Control Officer radios orders to the unit); however, subject matter experts typically indicate that battlefield intelligence is commonly provided in the form of static print (SGT D. Hanson, SSG C. Abbott, SSG A. Labbee, SFC N. Jorgensen, personal communication, 5 November, 2013). Static-based intelligence offers information about the particular mission, whereas procedural 
directions are often printed in text (static print). Though less common, a warfighter may also be provided with intelligence including pictures or diagrams to identify a location or provide a set of orders, known specifically as signals intelligence (Army Doctrine Reference Publication (ADRP) 2-0, 2012). Specifically, a print-out from "Google Maps" may be used as a form of signals intelligence to communicate the location of hostile forces or a hostile area. If given a choice between using printed directions to a hostile location or an image from "Google Maps", it is important to know which portion of the intelligence (static print or graphics) the warfighters will rely on more during a critical mission, especially when faced with strict time pressure.

Krupenia et al. (2012a) discovered warfighters are likely to rely on only one modality of intelligence to complete a task instead of a combination of modalities. In this experiment, Krupenia et al. (2012a) provided Polish warfighters with a Personal Digital Assistant (PDA) device to determine how warfighters collect and use information on the battlefield. The PDA offered warfighters five modality choices (photo, video, icon, text, and audio) to complete a simulated reconnaissance task and participants were free to use all of the modalities or any combination to complete the task. The researchers found warfighters were more likely to use the video and photo modalities more than the others and were likely to use only one modality. However, Krupenia et al. did not establish clear consequences for not completing the task. Therefore, the warfighters were not under any pressure to perform.

In a subsequent study, Krupenia et al., (2012b) asked warfighters to play the role of a Command and Control Officer tasked with communicating and receiving information. The participants were given the option to communicate information using 
photos, videos, audio, or text. Participants were also given the option to choose the modality by which they wanted to receive information. Warfighters preferred to send information with video, but preferred to receive information with photos or audio more than the video and text options. In discussion of the findings for both studies, Krupenia et al. (2012) argued that the preference for receiving information by photos or audio stems from the desire to pinpoint crucial information. Receiving information by text or videos places a requirement on the individual to search for the critical information from among irrelevant background information, or "noise."

Some researchers (e.g., Eitel, Scheiter, Schuler, Nystrom, \& Holmqvist, 2013; Gellevij, Van der Meij, De Jong, \& Pieters, 2002; Glenberg \& Robertson, 1999) have explored the variability of task performances when participants were trained using different instructional media and modalities. However, none have instituted a realistic battlefield scenario within which an individual is tasked with completing a critical mission. The purpose of this experiment is to determine whether textual descriptions or image instruction yields better task performance in a simulated critical military scenario.

\section{Static Instructional Modality Paradigm}

Researchers have implemented the static instructional modality paradigm to determine whether text or graphics (diagrams) are better for short term memory tasks. Findings have been equivocal; some researchers have determined text to be more effective for learning and task execution (e.g., Glenberg \& Robertson, 1999), whereas others have found images and diagrams to be more effective (e.g., Nelson, 1979; Nelson, Reed, \& McEvoy, 1977; Nelson, Reed, \& Walling, 1976).

Glenberg \& Robertson, (1999) first proposed the Indexical Hypothesis, which 
posits that text may require more cognitive effort to process. Text instructions do not allow an individual to use sensory processing to relate to material presented in images. Rather, text must be mentally translated into objects and actions related to the environment, or past experiences. In cognitive terms, this implies that the use of the visuospatial sketchpad is prevented. The visuospatial sketchpad refers to a subsystem of working memory that allows the maintenance and manipulation of visual and spatial images. Consequently, by mentally translating text, an individual employs more mental effort and "practice." Therefore, according to Glenberg and Robertson (1999), the information will be processed and remembered better from an image.

\section{Pictorial Superiority Effect}

In a series of experiments by Nelson et al. $(1976,1977,1979)$, images were shown to be superior to their textual counterparts due to the Pictorial Superiority Effect. The Pictorial Superiority Effect posits images to be better forms of instruction because they allow an individual to mentally "visualize" information using sensory processing in lieu of the mental transformation required to process textual information.

The Pictorial Superiority Effect seems to depend on the type of learning task being assessed. Although some research has found images and diagrams to be better for short-term memory recall, it is also evident that different modalities of instruction have advantages and disadvantages for learning, recognition, and task performance (van Hooijdonk \& Krahmer, 2008). To elaborate, text is communicated in a linear format and requires abstract linguistic processing; pictures are communicated in static symbolism and require sensory processing (Zwaan \& Radvansky, 1998). Images are not inhibited by a linear structure and may be more effective for representing nonlinear relationships (van 
Hooijdonk \& Krahmer, 2008). Processing text requires more cognitive effort, because processing written language first requires the formation of a cognitive mental model and then dissection of the model to properly execute the task (Glenberg \& Robertson, 1999). In cognitive terms, processing text requires activation of the phonological loop. Humans understand and process text by first cognitively fabricating a propositional symbolic illustration of the text's semantic content, and then using this illustration to build an analog mental model of the information (Kintsch \& van Dijk, 1978; Morrow, Greenspan, $\&$ Bower, 1987). Conversely, processing static images requires less mental effort because a picture communicates necessary procedural information. Given the choice between text and pictures, a learner may choose to use the text to form a symbolic representation of the information when faced with understanding an abstract or complex concept. In opposition, the learner may choose to ignore the text and use the graphic to form a model representation of the information (Schnotz, 2010). Plainly, processing text may be better for learning and encoding complex information to form a symbolic cognitive model for later reference. Pictures, conversely, communicate information that can be dissected immediately, because the formation of a symbolic cognitive model is essentially unnecessary.

Text is often used to communicate complex information. Scientific literature, for example, documents theories, hypotheses, and findings using text. Most articles include limited images or graphics, but the reader cannot understand the article or experiment without relying on the printed textual content. The method of using text to communicate complex information is used because text is associated with abstract learning (Eitel et al., 2013). However, in the past few decades, scientists have questioned this primary form of 
static communication and have started to study whether images, diagrams, or dynamic forms of educational materials are better for learning as they require less cognitive effort to integrate and encode.

Nalu (2011a) examined whether training with comic strips would lead to better decision-making performance and speed compared to training with text. Nalu (2011a) presented Navy officers with either a comic strip or short text description regarding a military scenario and then questioned them on their understanding and comprehension of the scenario. In this experiment, Nalu (2011a) did not find any significant performance or speed differences, but the researcher did find that comic strips took less time to read and understand $(M=2.33$ seconds $)$ compared with textual descriptions $(M=2.67$ seconds). Nalu (2011a) attributed her overall non-significant findings to her population; Navy officers with considerable training and experience may not differ when assessing training modalities due to their expertise. In addition, Nalu (2011a) included text in the comics. As text was included in both conditions, this experiment may not have accurately assessed if comic strips (images) were more beneficial to decision-making performance and speed. Further, Nalu (2011a) did not use color in the comic strips. The absence of color and inclusion of text in both conditions may have influenced the results of this study. In a subsequent experiment, Nalu (2011b) assessed whether comic strips with varying levels of detail (fidelity) had an effect on decision-making speed or performance. Though the researcher did not find any significant differences, her population noted a preference for comics with a medium level of fidelity compared with low or high fidelity.

Relating to the Pictorial Superiority Effect, many researchers (e.g., Buckner et al., 
2000; McBride \& Dosher, 2002; Paivio \& Csapo, 1973; Schnotz, 2002) have found that pictures are relied upon more than words for short-term memory recall tasks. No research, however, has studied whether humans rely on pictures or printed text more in a critical scenario, or a situation that may have an outcome with severe consequences resulting in death. The primary focus of this research is to determine whether images continue to be relied upon more in a highly critical scenario, defined as a scenario that has the potential for loss of life.

Pictures have been demonstrated as superior forms of facilitating information retention for short-term memory tasks (Bowen \& Standing, 1976; Paivio \& Csapo, 1973; Peloquin, 1979). Participants in the Paivio and Csapo (1973) experiment were presented with a group of objects (nouns) presented in text, and a group of objects presented with images. Participants were given five minutes to study both lists, and later asked to recall as many items as possible. Data analyses indicated more items from the list of pictures were recalled when compared with the list of nouns, and participants reported the pictures were easier to recall because they could "visualize" them better than the nouns presented in text.

Mcbride \& Dosher (2002) conducted a similar experiment in which participants were again asked to study lists including 40 pictures and 40 textual items, and to later recall as many items as possible. They found that participants recalled an average of 16.96 pictures correctly, whereas they recalled only 12.52 words correctly. These findings are consistent with the Pictorial Superiority Effect for short-term memory recall. In a more complex experiment, Nelson et al. (1976) presented participants with a list of pictures and text labels, equated for conceptual similarity and concreteness. These 
researchers also found pictorial superiority in memory recall; however, only with pictures exhibiting low schematic similarity. With high schematic similarity, memory recall for text was superior. Schematic similarity is defined as how much an item relates to the nature of its schema, or how similar it is to its origin or representation (Azizian, Freitas, Watson \& Squires, 2006). These results imply either 1) memory recall for pictures is superior only with abstract or complex concepts or 2) memory recall for textual labels and graphics is a qualitatively different and requires more scientific observation. The latter explanation was addressed by Buckner, Logan, Donaldson, \& Wheeler (2000).

Buckner et al. (2000) demonstrated through fMRI studies that the left frontal cortex of the brain is illuminated when participants are intentionally trying to remember the definitions or concepts linked with specific words written in text, referred to as deep encoding. When participants are presented with semantic (meaning-based) elaboration upon verbal materials, additional portions of the brain are illuminated along with the left frontal cortex (Chee et al., 1998). However, when participants are presented pictures of an object, portions of the brain are illuminated in the right hemisphere along with the left frontal cortex regions that are used for encoding verbal information (Buckner et al., 2000). This finding suggests that pictures require the same cognitive mechanisms in the left hemisphere used for textual encoding, while also using additional cognitive mechanisms in the right hemisphere for graphical perception and integration. This is important, as it may suggest that nonverbal information (images, graphics) are more useful for learning than textual information because nonverbal informational cues utilize more areas of the brain, allowing for more cognitive integration. This is consistent with the dual-encoding theory, detailed below. In addition to this finding, other researchers 
have found that the recall of nonverbal information, specifically images and graphics, may be processed by the visual cortex in addition to portions of the parietal and occipitaltemporal regions of the brain (Nyberg et al., 2000; Wheeler et al., 2000; Zatorre et al., 1996).

\section{Dual-Coding Theory}

First proposed by Paivio (1971), dual-coding theory is based on the concept that there are two separate cognitive coding mechanisms that are activated when humans form mental representations. One mechanism is responsible for coding language and verbal documentation, whereas the other mechanism is responsible for coding nonverbal objects (images). Elaborating further, Standing and Smith (1975) suggested that written language and auditory language are coded by the same cognitive mechanism, and there is little difference in the way these types of information are cognitively processed when compared to the processing of nonverbal stimuli, such as images. Essentially, early dualcoding research suggested that language, including written text, is processed in a qualitatively different way than images.

Schnotz and colleagues (Schnotz \& Bannert, 1999; Schnotz, 2001; Schnotz, 2002) explained that words and sentences are normally processed and encoded by the verbal system, whereas pictures and images are processed and encoded by both the imagery system and the verbal system. This explanation is consistent with the Pictorial Superiority Effect, as it describes why images are more likely to be remembered than text; images provide richer and more comprehensive information because they are encoded by two cognitive systems instead of one.

Schnotz's (2001; 2002) new integrated model (Figure 1) describes two separate 
branches of cognitive representations; the descriptive branch and the depictive branch. The descriptive branch encompasses physical text stimuli, an internal mental representation of the text's surface structure, and a propositional representation of the text's semantic meaning. The depictive branch includes physical graphical stimuli, an internal visual image of the picture, and a mental model of the image's subject matter.

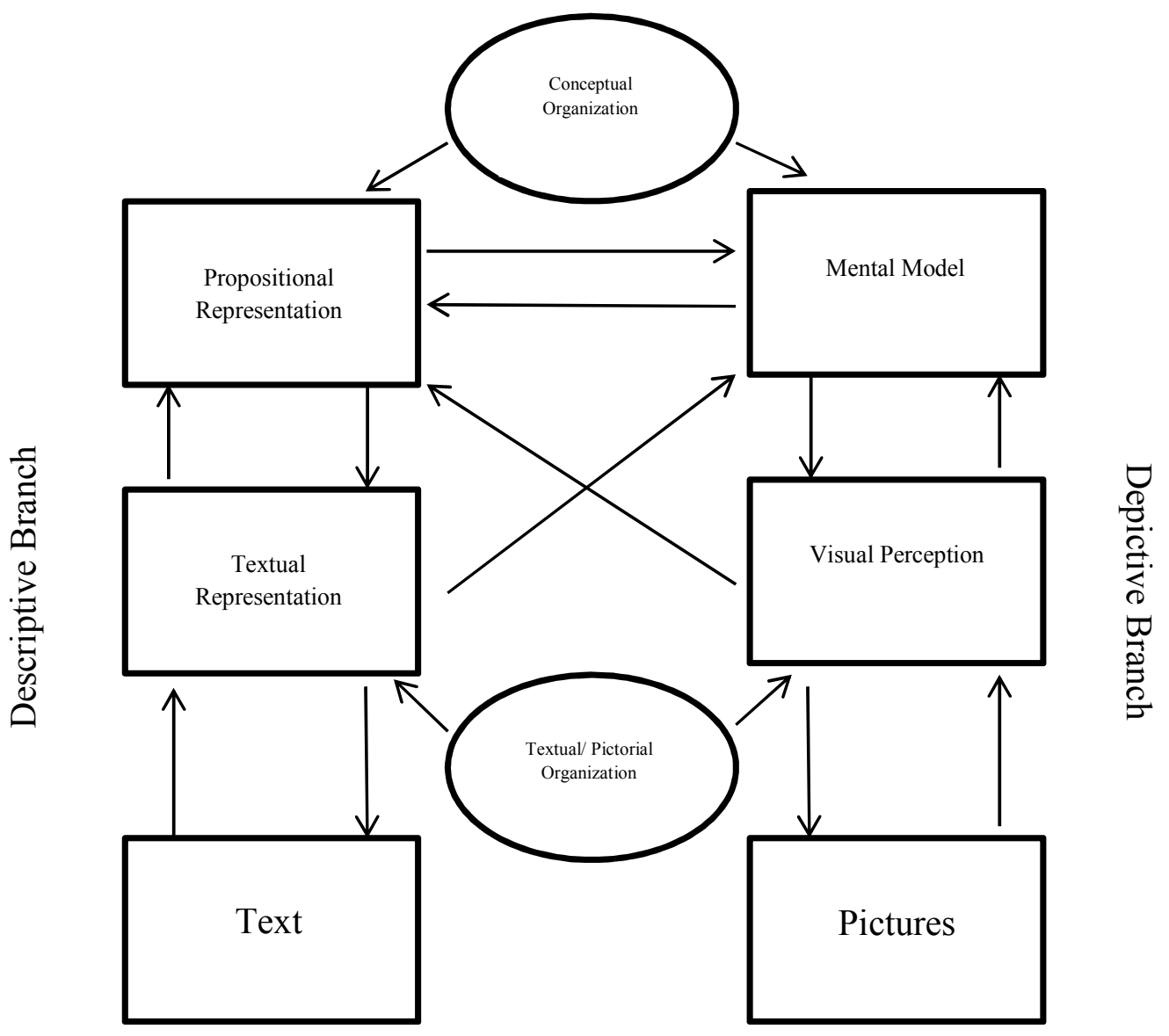

Figure 1. Simplified model of text and picture integration. Adapted from "Towards an Integrated View of Learning From Text and Visual Displays" by W. Schnotz, (2002), Educational Psychology Review, 14 (1), p. 109. 
When integrating textual information, the reader forms a mental representation of the text, generates a propositional representation of the semantic content (meaning of the text), and then creates a cognitive "textual" mental model (van Dijk \& Kintsch, 1983; Schnotz, 1994; Weaver et al., 1995). Processing pictures requires a similar process; however, humans use the capacity of both the verbal and nonverbal coding systems, which ultimately leads to the processing and coding of more information (Gellevij et al., 2002). In cognitive terms, processing and coding information is done by the central executive portion of working memory.

To summarize, dual-coding theory posits two independently operating processing systems; one for textual information and one for graphical information. Although these types of information are processed separately, they are not completely isolated from one another. Connections are made between physical stimuli and their mental representations and separate connections are made between visual and verbal representations, likely because of the hemidecussation mapping of the brain (Beagle, 2009; Mayer \& Sims, 1994; Paivio, 1991). Pictures are more comprehensibly processed because there are two separate cognitive mechanisms involved in the encoding process instead of just one process. This allows for more available cognitive resources when encoding pictorial information, making the process easier and more efficient.

The current study will determine whether pictures or text are more relied upon in a critical scenario which requires a short-term memory recall task. According to the theories discussed earlier, pictures should be more useful than textual information, as pictures are processed more comprehensibly and quicker by the human brain. As critical scenarios require immediate and accurate response and task execution, it is important to 
determine if pictures are superior to lexical instruction.

\section{Information Processing Theory}

Multiple resource theory suggests that multiple cognitive resource pools are available to process information pertinent to different types of tasks. The multiple resource model explains multiple task performance and interference that central resource theories and bottleneck theories of attention do not address (Wickens, 1988). Simply put, cognitive resources are able to operate independently as they enable performance of complex multiple tasks. This theory explains that certain tasks may be qualitatively different, requiring separate processing procedures, as proposed by dual-coding theory. To explain, Wickens (2010) distinguishes between visual and auditory biological structures. Whereas the eyes and ears may operate independently (allowing for multiple task performance), two visual tasks or two auditory tasks cannot be processed together efficiently. Multiple resource theory also addresses verbal and spatial tasks. According to the theory, auditory and spatial tasks can be performed together, as can visual and verbal tasks. However, two auditory, two spatial, or two verbal tasks create interference when performed together.

Wickens (2008) describes that different cognitive processes occur in different portions of the brain; verbal and linguistic processing exist in the right and left cerebral hemispheres whereas visual and perceptual processes occur in both the visual cortex and central sulcus portions of the brain. This claim lends additional credence to dual-coding theory, as dual-coding theory posits that the processing for textual and pictorial information occurs in different portions of the brain. The discrepancy between multiple resource theory and dual-coding theory is that dual-coding theory suggests that pictorial 
information is processed by both linguistic and visual cognitive mechanisms, while Wickens suggests that there is only one cognitive mechanism devoted to processing each information modality.

Concerning workload, Wickens (2008) describes two types of tasks: A task in which cognitive demand is less than the cognitive resources (mental processing ability) available, and a task in which cognitive demand exceeds the available cognitive resources. In the latter task, an individual should experience cognitive performance degradation when faced with a task that depletes available cognitive resources. Whereas multiple resource theory deals mostly with multiple tasks competing for available resources, there are some important implications pertaining to workload in the proposed study. A modality that uses cognitive resources more comprehensibly should result in less performance degradation, because the brain processes the information more efficiently. Therefore, when comparing modality presentation for a target search in a virtual environment, the modality requiring fewer cognitive resources should present itself with better individual performance. In the current study, the modality requiring fewer cognitive resources should be images, as suggested by the previously referenced theoretical models.

\section{The Critical Decision Method}

First proposed by Klein et al., (1989), the critical decision method posits that expertise emerges during non-routine tasks. A critical task is, in many ways, an example of a non-routine task. The critical decision method states that once an unexpected event has occurred, an individual will not take the time to construct mental models that represent a cost/benefit analysis of a given response. Instead, the individual will react to 
the scenario using the most efficient cognitive resources available.

Studying power plant operators' responses to critical incidents, Carvalho et al. (2005) found that $80 \%$ of responses were based on pattern recognition and implicit conditions rather than relying on standard operating procedures. Plainly, operators immediately responded to urgent incidents using expertise and pattern recognition instead of trying to remember complicated mental models of information learned during training. This finding is reminiscent of the Pictorial Superiority Effect, as operators rely on displayed graphical patterns to process efficiently and respond promptly.

\section{Stress, Performance, and Criticality}

In line with information processing theory (Wickens, 1996), military personnel commonly experience cognitive and psychological impairment after exposure to lengthy stressful situations, fatigue, and sustained training assignments. However, according to several researchers (e.g., Callister et al., 1999; Elsmore et al., 1992; Harris \& Hancock, 2005; Slaven \& Windle, 1999) cognitive impairment does not occur when military personnel are exposed to short-term critical scenarios and tasks. Harris \& Hancock (2005) conducted a study in which they examined military cognitive degradation after exposure to long-term stress. The researchers measured cognitive performance and psychological state prior to one week of intense naval field training, and again immediately following the training. The researchers found in their post-training measurements that participants' immediate responses to stress were as accurate as their pre-training baselines. Harris and Hancock (2005) concluded that cognitive ability is not impaired immediately following exposure to a critical scenario, or a stressful task, but cognitive performance does decay rapidly with increased or sustained exposure to 
stressful situations. Interestingly, the same researchers found that cognitive performance actually improved immediately following exposure to a critical scenario, but decayed in accordance with prolonged scenario length. Harris and Hancock (2005) attribute these findings to participants increasing their performance efforts towards the critical task, essentially masking the cognitive decrement they may be experiencing due to the increased demands and mental workload. The researchers did not note exactly for how long this extra effort could be maintained.

For example, a warfighter will experience cognitive impairment after sleep deprivation and sustained training demands, but should not experience cognitive impairment when presented with a critical mission or task that requires immediate response and task execution. Therefore, criticality should not affect the cognitive processing of intelligence information, or the way specific modalities of information are cognitively integrated and processed.

Criticality is a concept that has not frequently been studied in psychological literature. One reason for the lack of research is that the definition of criticality is broad and can be ambiguous. Nonetheless, studying criticality is crucial to understanding battlefield behavior and understanding jobs that require operators to perform tasks in high stress situations. For the purpose of this study, "high criticality" is defined as a task that has potentially life-threatening consequences (Bliss et al., 2013; Hanson et al., 2014). A warfighter asked to locate a live bomb before it detonates (potentially threatening the lives of troops and civilians) is an example of a high criticality task. "Low criticality" is defined as a task absent of life-threatening consequences. For example, a warfighter may be asked to locate a laboratory holding uranium stockpiles. While still important, the low 
criticality task does not have direct life-threatening consequences.

Bliss and McAbee (1995) examined perceived criticality in response to alarm systems. They found that alarm response performance and alarm response frequency varied as a function of criticality; low alarm criticality resulted in more accurate responses to the warning systems. However, the researchers did not find a significant difference in ongoing task performance between high and low criticality conditions in their experiment. As noted, criticality has many definitions in scientific literature. Bliss and McAbee (1995) told participants that more points would be deducted from their overall performance score in their high criticality condition compared with their low criticality condition. The lack of significant findings for criticality may be attributed to participants being unable to connect point loss with real world consequences.

In two similar experiments (Bliss et al., 2013; Hanson et al., 2014), task criticality was manipulated to determine the effects on operator control strategies. Bliss et al. (2013) manipulated task criticality in the form of time pressure; participants were informed that negative performance would have detrimental consequences. Bliss et al. (2013) found that participants performed better under strict time pressure, or high criticality, compared with no pressure. Hanson et al. (2014) conducted a similar experiment in which participants were told a priori that poor performance would result in the loss of life for hypothetical team members. The findings showed that the criticality manipulation influenced performance; acquisition time was quickest for high criticality targets.

Kliegel, Martin, McDaniel, and Einstein (2004) manipulated the importance of a task to determine the effect on prospective memory performance. They found that 
performance with a prospective memory task was better when the task was deemed to be of high importance. They did not establish consequences for completion or poor performance; however, they did tell participants to focus on either a primary or secondary task. When participants were told the secondary task was more important than the primary task, prospective memory performance increased for the secondary task. Conversely, when participants were told the primary task was more important, performance improved for the primary task. Although this is not directly analogous to the definition of criticality in the proposed experiment, it does suggest that the assigned importance of a task affects memory performance.

\section{Study Purpose}

Considering the impact of the Pictorial Superiority Effect on short-term memory recall tasks, the purpose of this current work was to determine if the Pictorial Superiority Effect would apply when participants were presented with a critical scenario: searching for important target items in a simulated battlefield environment. From the research findings of Krupenia et al. (2012), warfighters are more likely to rely on only one modality of information when using obtained intelligence in a reconnaissance task. According to Harris and Hancock (2005), warfighters should not experience cognitive decrement when presented with a critical task requiring immediate response. In line with dual-coding theory, pictures do not require as much cognitive effort to understand and encode. Therefore, in a virtual search task, pictures of target items should have yielded faster response times than a description of the target item written in text, especially when the task was critical. According to Bliss et al. (2013), Hanson et al. (2014) and Kliegel et al. (2004), the assigned criticality and importance of a task affects performance. From 
these findings, individuals were expected to perform better in a critical task involving short term memory recall. Finally, as previously discussed, it was important to study the information modality relied upon during a critical task. Although theory has yet to address these particular variables in combination, it is possible that findings could have implications on the way training is addressed for jobs involving critical outcomes. Instead of supplying warfighters with lengthy instruction manuals for use in a critical scenario, it may be more beneficial to provide warfighters with images or diagrams. This can also be expanded to additional employment domains to include medicine, power plant operators, pilots, and other critical task operators.

Hypothesis 1- Participants will collect pictorial targets faster than objects presented in text in the high criticality condition (Bowen \& Standing, 1976; Mcbride \& Dosher, 2002; Paivio \& Csapo, 1973; Peloquin, 1979). Though none of the previously mentioned experiments investigated the Pictorial Superiority Effect under varying levels of criticality, all of the researchers demonstrated that pictures are superior forms of instruction for performance in short-term memory recall tasks. The current study tested whether the Pictorial Superiority Effect remained constant while the participant was under pressure or stress when faced with a critical task. To answer this question, researchers presented participants with several target items to locate in a virtual battlefield environment; some of the target items were presented using textual descriptions, and some of the target items were presented with images.

Hypothesis 2- More targets will be accurately collected in the high criticality condition (Bliss et al., 2013; Harris \& Hancock, 2005; Hanson et al., 2014; Kliegel et al, 2004). Kliegel et al. (2004) demonstrated that participants perform better on memory 
tasks when the task is deemed to be of greater importance. From this finding, more targets were expected to be accurately collected in the high criticality condition. Additionally, many researchers (e.g. Callister et al., 1999; Elsmore et al., 1992; Harris \& Hancock, 2005; Slaven \& Windle, 1999) claim that a critical task does not impair cognitive ability unless the individual is fatigued or exposed to long-term stressful situations. Harris \& Hancock (2005) demonstrated that performance increases initially after exposure to a critical scenario. Bliss et al. (2013) and Hanson et al. (2014) demonstrated that manipulating task criticality does influence operator performance.

Hypothesis 3- Participants will accurately collect more pictorial targets in the high criticality task. In line with dual-coding theory and the Pictorial Superiority Effect, pictorial modalities should elicit the best performance, as fewer cognitive resources are needed for short-term memory recall tasks, leading to more efficient cognitive processing. Therefore, this hypothesis predicted that pictorial targets would be located with greater accuracy in the high criticality condition.

\section{Hypothesis 4- Fewer overall errors will be committed in the high criticality} task (Carvalho et al., 2005; Klein et al., 1989). In line with the critical decision method (Klein et al., 1989), participants should be less likely to make errors in the high criticality condition of this experiment because they will rely on the most efficient cognitive processes to complete the task. This implies that participants would be more accurate when locating targets in the high criticality task than in the low criticality task. Pictorial targets should be easier to process according to the Pictorial Superiority Effect and dualcoding theory. Additionally, participants should make fewer errors in the high criticality condition because they will rely on their most efficient cognitive resources when locating 
targets.

\section{Hypothesis 5- Participants will experience higher cognitive workload when} attempting to locate targets presented in the high criticality condition. (Harris \&

Hancock, 2005). In line with the findings of Harris and Hancock (2005), exposing warfighters to a critical scenario does not result in cognitive decrement and may actually improve cognitive performance for a short time. Therefore, this hypothesis predicts that military participants would experience higher cognitive workload when exposed to the high criticality condition, however, overall performance in the task would not suffer.

\section{Modality/Criticality Interaction Research Question}

As noted, prior research has not examined whether images or text represent better forms of instruction for a critical task. Though empirical evidence is not available to support this, a significant interaction was expected between the main effects of criticality and information modality. This interaction was expected because it seems logical that as the criticality of a task increases, the capacity to process difficult lexical or lengthy instructions decreases. Similarly, as the criticality of a task decreases, it seems logical that the cognitive ability to process pictorial instructions increases. 


\section{METHOD}

The current study asked participants to locate and collect objects in a virtual environment. The objects were presented using either images or textual descriptions. For example, a participant may have been asked to navigate through the environment to locate a wedge of cheese. The participant was then either presented with an image of a wedge of cheese, or a more complex description of the wedge of cheese (for example: an edible triangular object that is yellow in color). The text descriptions did not include distractor information, but they were more complex than a simple definition of the target item to mimic the effect that lengthy instruction manuals may have on critical search tasks. Before being asked to locate the string of objects, the participant was told the criticality of the condition. For example, the participant was told failure would result in the death of their team members in the high criticality condition.

\section{Design}

The current study employed a $2 \times 2 \times 2$ mixed quasi-experimental design (Maxwell \& Delaney, 2004) using the Virtual Reality Assessment Module Multiple Errands Task (VRAM-MET) as an experimental activity. The independent variables were instruction modality (text or pictures) of the target instruction presentation and the task criticality level (high or low) of the experimental conditions. Modality and criticality were manipulated as within-groups variables, whereas participant experience was treated as a grouped between-groups variable. Dependent variables consisted of acquisition time (in seconds), errors (commission and omission), workload, and target accuracy (see Table 1). Military personnel having a history of deployment and undergraduate students with no history of deployment were tested, and were randomly 
assigned to counterbalanced criticality conditions.

Table 1

Experimental Design

\begin{tabular}{|l|l|l|l|l|l|}
\hline \multicolumn{3}{|c|}{ High- Low Criticality } & \multicolumn{3}{c|}{ Low- High Criticality } \\
\cline { 2 - 3 } \cline { 6 - 7 } & Military & Student & & Military & Student \\
\hline Text & $(D V)$ & $(D V)$ & Text & $(D V)$ & $(D V)$ \\
\hline Pictures & $(D V)$ & $(D V)$ & Pictures & $(D V)$ & $(D V)$ \\
\hline
\end{tabular}

Table $1.2 \times 2 \times 2$ mixed design. Instructional modality (pictures vs. text) and task criticality (low vs. high) were treated as within-subjects variables. Participant experience (undergraduate student vs. military personnel with deployment history) was treated as a random variable.

\section{Participants}

Forty participants were recruited for this study. Twenty undergraduate student interns were recruited from NASA-Langley Research Center during a summer internship program. Their ages ranged from 18-26; undergraduate participants included 11 males and 9 females. Twenty military personnel with deployment history were recruited with ages ranging from 19-32; military participants comprised of 16 males and 4 females. Undergraduate and military participants were given a ten dollar Starbucks gift card for their participation, provided they completed the entire study. The gift card was not based on performance and enticed participation in the study. Military personnel were recruited from Old Dominion University, Ft. Benning, Ft. Leavenworth, Ft. Carson, Ft. Bliss, Ft. Eustis, and Naval Station Norfolk. They received the same gift card for participation 
following completion of the study. Military personnel were tested off-base during nonduty hours.

Of the forty participants recruited for this study, twenty were undergraduate interns and twenty were military personnel with deployment history. Participants ranged in age from $18-35(M=23.72 ; S D=2.86)$ and more males were recruited than females. The military population consisted of 16 males and 4 females whereas the student population consisted of 14 males and 6 females. The mean age for the twenty military participants was $24.9(S D=1.97)$ whereas the mean age for student participants was 22.7 $(S D=2.12)$. Military participants reported playing video games an average of 7.2 hours per week $(S D=4.61)$, whereas student participants reported playing video games an average of 13.7 hours per week $(S D=2.01)$.

Of the twenty warfighters recruited, 13 were US Army Soldiers whereas seven were US Navy Sailors. All military participants had a history of deployment to Operation Iraqi Freedom (OIF), Operation Enduring Freedom (OEF), or both. Military participants had an average of 3.75 years in service. Seventeen military participants were enlisted whereas three were officers. Of the US Army participants, six had a Military Occupational Specialty (MOS) relating to the medical field. Other US Army MOS's related to communications, infantry, aviation and ammunition. Navy MOS's included ship maintenance, cryogenics, aviation, and submarine communications.

\section{Materials}

\section{Virtual Reality Assessment Module/ Multiple Errands Task}

The Virtual Reality Assessment Module (VRAM) virtual environment-based simulation was developed in 2012 with funding by the Office of Scientific Development 
by researchers at Old Dominion University and computer programmers at A2-T2, Inc. The purpose of this environment was to simulate a typical meet-and-greet military mission, allowing warfighters to experience cognitive demands similar to those required in military combat. Within the simulation, researchers incorporated a version of the Multiple Errands Test (Shallice \& Burgess, 1991). Set in a Middle-Eastern marketplace, the participant controls an avatar warfighter, and must explore the environment to complete a series of "errands" in a limited amount of time. These errands include remembering the opening and closing times of virtual stores and remembering to purchase certain items within the marketplace. The task relies heavily on a participant's prospective memory. For the proposed study, the multiple errands test within VRAM was adapted as a task to determine whether participants processed information and performed search tasks more efficiently when presented with either pictorial or textual information, and when searching under conditions of low and high criticality.

Shallice and Burgess (1991) first developed the Multiple Errands Test. Using a task designed to compare those with frontal lobe damage against a control sample matched for age and intelligence, Shallice and Burgess ultimately found the MET to be an ecologically valid assessment with a coefficient of .64 and an internally reliable assessment with a coefficient of .77. Adapting the original paper-based version, a virtual version of the MET was integrated into the VRAM scenario.

Though the multiple errands test (MET) was developed primarily to discriminate individuals with brain injuries from individuals with normal brain function, the current experiment included only participants with normal brain function. A history of traumatic brain injury or other brain injury could have hindered a participant's ability to accurately 
navigate through the virtual environment, introducing uncontrolled error variance into the overall findings. For the current research, the MET environment was used in a diagnostic fashion to assess whether text-based or picture-based procedural instructions led to superior task performance accuracy, acquisition time, errors of commission, and workload during a critical task.

Demographic Questionnaire. Participants first completed an Informed Consent Form (Appendix A) and then completed a demographic questionnaire (Appendix B) that included information about age, sex, video-game experience, and visual color deficiency. Participants indicating visual color deficiency were excused from participation.

Military Background Questionnaire. Participants completed a military background questionnaire, indicating military branch, rank/ grade, military occupational specialty (MOS), and a detailed deployment history including questions relating to PostTraumatic Stress Disorder (PTSD). Any military personnel indicating symptoms or a history of PTSD were excused from the study, as the simulated critical scenario could have potentially triggered flashbacks. Undergraduate students without military experience marked "N/A" and moved on to the brain-function questionnaire. Undergraduate students with service backgrounds including deployments were considered part of the military personnel group.

Brain - Function Questionnaire. Participants completed a brain function questionnaire (Appendix C) that provided information about a history of traumatic brain injury or concussion. Participants indicating a history of brain injury were excused from participation. 
Subjective Workload. Participants were asked to complete the NASA-Raw TLX (computer version) following each criticality condition. Participants were asked to subjectively score their cognitive demand relating to the following subscales: mental demand, physical demand, temporal demand, performance, effort, and frustration. These data were averaged to yield total means for each subscale relative to participant population.

\section{Procedure}

Undergraduate interns and military personnel were tested at an off-site testing location during non-duty/ work hours. All data were collected using the same laptop computer to ensure standardization of experimental stimuli presentation. Upon arriving at the testing location, participants read and signed the Informed Consent Form (Appendix A), which detailed the potential benefits and risks of this study. The Informed Consent Form also provided a brief summary of the experiment and notified the participant that he or she was free to terminate participation at any time. After completing the consent form, participants completed the remaining demographic and screening questionnaires. One participant indicated visual color deficiency on the Demographic Questionnaire (Appendix B) and so was excused. After completing the Military Background Questionnaire (Appendix C) and Brain-Function Questionnaire (Appendix D), participants who indicated a history of PTSD or brain injury were also excused. Two participants were excused for having a history of PTSD.

The experiment lasted approximately one hour, and was approved by the Old Dominion University's Institutional Review Board before data collection began. All participants were required to complete an Informed Consent Form (Appendix A), 
Demographic Questionnaire (Appendix B), Military Background Questionnaire (Appendix C) and a questionnaire to ensure participants did not have a history of brain injury (Appendix D). Additionally, participants were screened for visual color deficiency (self-report), as color deficiency could have hindered the ability to locate objects in the virtual environment using the provided pictures.

Participants were seated at a computer and read general instructions by the researcher (Appendix E). The researcher repeated the instructions as many times as necessary until the participant indicated comprehension. The instructions indicated that the participant was required to navigate through the virtual environment and locate various items. The participant was then given 10 minutes to practice navigation and locate items in the virtual environment. The researcher verbally instructed the participants to locate specific objects during the familiarization session; the experimental session did not begin until the participant was able to correctly locate two items. Participants then began the testing session in a condition of high or low criticality (randomly determined).

The participant controlled an avatar warfighter tasked with navigating through a virtual marketplace to collect various objects (Appendix F). Each object was presented in one of two modalities: images or text. The participant was presented with one object at a time; either a picture of the object or a brief description of the object written in text (Appendix G). The researcher measured the time it required (in secs) for the participant to locate the object and then the participant was then presented with the next object. This process continued until all sixteen objects in the condition had been collected. Each participant performed under both criticality conditions. The session began with either low or high criticality and converted to the other criticality level midway through the task 
(after eight targets). The session's starting criticality was counterbalanced; initial criticality level was assigned at random by the researcher. In the high criticality condition, participants were read a script (Appendix H) describing the importance of collecting all of the appropriate objects, and the consequences that would occur if all of the objects were not collected accurately (members of the participant's military unit would die if they were unsuccessful). The low criticality condition was similar, but the consequences for collecting incorrect objects were presented as less dire than in the high criticality condition; losing rank (a demotion) in the military. Midway through the task, the participant received a simulated radio transmission explaining that the criticality of the mission had changed. The starting task criticality level was randomly assigned to each participant and the order of target presentation was fixed, but had an equal number of each target modality presented in random order.

Acquisition time was measured as the total time (in seconds) required for the participant to reach and acknowledge the location of a target from a standard starting position within the scenario. An overall cutoff score was two minutes, meaning if a specific target was not located within two minutes, the target was coded as an error. However, participants continued to search for the target past the two minute mark until they located it, and their acquisition time data was coded appropriately. Acquisition time was measured by the researcher observing and timing individual target locations.

Errors of commission were noted by the researcher as participants committed them. Possible specific errors are described in greater detail in the Procedure section. Workload was measured using the NASA-Raw TLX computer version. Participants completed the questionnaire following completion of the experimental task. 
The NASA-Raw TLX has acceptable test-re-test reliability, with coefficients ranging from 0.526 to $0.752(p<0.01)$ (Xiao, Wang, Wang, \& Lan 2005). This measure has also shown good split-half reliability (internal consistency); $\alpha>.80$ (Xiao et al., 2005; Hart, 1988).

Accuracy was defined by the total number of each target modality collected (pictures or text). Scores for each target modality were recorded separately. Participants had the ability to locate 16 targets; 8 targets presented in each modality. A participant's maximum accuracy score is 16 , or $8 / 8$.

Four participants (two undergraduate students and two warfighters with deployment history) were pilot-tested to assess the strength of the variable manipulations and to ensure means were trending in the direction of the proposed hypotheses.

\section{High/ Low Criticality Task}

Participants were read instructions for the high/low criticality task by the researcher (Appendix H). After affirming that they understood the instructions, participants were presented with information about the first object to collect in the environment. Participants were allowed to view the representation of the object (pictorial or text) for 30 seconds, and then navigated through the environment to locate the item. Participants began at a specific location, located the item, and returned to the designated starting point (Appendix F). The researcher then manually recorded the time it took (in seconds) for the participant to correctly locate the object, and any errors the participant made during the object location process. The participant was then required to return to the starting position before being presented with the next object; however, timing stopped once the object was found and the participant verbalized to the researcher that the target 
had been located. Possible errors included: returning to the incorrect position after locating an item, locating an incorrect item, failing to locate an item, or referencing any of the icons/ displays available in the virtual environment. Images of icons appearing in the virtual environment are presented in Appendix I (because the scenario was developed for a multiple errands test, there are actions that can be completed in the virtual environment that are not relevant to the current study such as radioing a commanding officer or referencing a virtual wallet). Any use of these additional features was considered an error. A table of possible errors is included below.

Table 2

Errors of Commission

\begin{tabular}{l|l|l} 
Error Types & Error Category & Error Description \\
\hline Type 1 & Commission & Locate incorrect item \\
\hline Type 2 & Commission & Return to incorrect starting position \\
\hline Type 3 & Commission & Reference irrelevant scenario screens \\
\hline Type 4 & Commission & Exceed time limit of 2 minutes per item \\
\hline
\end{tabular}

After returning to the starting position, the participant was given a new object to collect, and this process continued until all objects for the condition were collected. Once the participant had collected eight objects, a simulated radio call occurred, indicating that the criticality of the task had changed. This information was read by the researcher, and can be seen in Appendix H. Sixteen objects were retrieved in total (eight lexically presented, eight pictorially presented); a complete list of objects can be found in 
Appendix G.

After completing the experimental session, participants were asked by the researcher if they had any feedback about the experiment. They were thanked for their participation and given the gift card. Participants were then debriefed and dismissed. The testing session lasted approximately 1 hour. 


\section{RESULTS}

Data were inspected and coded to identify missing values and to ensure that the underlying distribution was normal. Hypotheses were tested using a series of mixed $2 \times$ $2 \times 2$ ANOVAs. If an interaction was present, the subsequent analysis included calculation of simple effects. A criterion alpha level of $p=.05$ was used to indicate statistical significance because it provides appropriate balance between the consequences associated with committing a Type I or Type II error .

Data were also inspected to determine whether outliers were present, and if variables were normally distributed. Mauchley's tests were conducted to address the assumption of sphericity. If sphericity was violated, a Geisser-Greenhouse correction was used for data interpretation (Maxwell \& Delaney, 2004).

\section{Accuracy}

Accuracy was examined by dividing the total number of objects correctly collected respective to each condition by the total number of modality specific objects available in each condition. Homogeneity of variance was assessed using Levene's tests; the results indicated that homogeneity of variance was adequate. Mauchly's test of sphericity indicated that the assumption of sphericity was not violated.

The ANOVA results are presented in Table 3. 
Table 3

Analysis of Variance Results for Target Accuracy

\begin{tabular}{lcccccc}
\hline \multicolumn{1}{c}{ Source } & SS & df & MS & $F$ & $P$ & partial $\eta^{2}$ \\
\hline Between Subjects & & & & & & \\
Experience (E) & 0.03 & 1 & 0.03 & 2.97 & 0.09 & 0.08 \\
Error & 0.36 & 38 & 0.01 & & & \\
& & & & & & \\
\hline Within Subjects & & & & & & \\
Modality (M) & 0.01 & 1 & 0.01 & 2.27 & 0.14 & 0.27 \\
M x E & 0.05 & 1 & 0.05 & 0.70 & 0.23 & 0.05 \\
Error & 0.19 & 38 & 0.01 & & & \\
Criticality (C) & 0.31 & 1 & 0.31 & 11.97 & 0.17 & 0.05 \\
C x E & 0.02 & 1 & 0.02 & 5.96 & 0.21 & 0.05 \\
Error & 0.332 & 38 & 0.01 & & & \\
M x C & 0.01 & 1 & 0.01 & 7.94 & 0.47 & 0.11 \\
M x C x E & 0.02 & 1 & 0.02 & 4.59 & 0.03 & 0.55 \\
Error & 0.61 & 38 & 0.61 & & & \\
\hline
\end{tabular}

Descriptive statistics were calculated for target accuracy and are presented in the following table. 
Table 4

Means and Standard Deviations for Target Accuracy

\begin{tabular}{|c|c|c|c|c|}
\hline Experience & Modality & Criticality & $M$ & $S D$ \\
\hline \multirow{4}{*}{ Military } & & High Criticality & 0.99 & 0.60 \\
\hline & Pictures & Low Criticality & 0.96 & 0.09 \\
\hline & \multirow[b]{2}{*}{ Text } & High Criticality & 0.94 & 0.50 \\
\hline & & Low Criticality & 0.99 & 0.50 \\
\hline \multirow{4}{*}{ Student } & \multirow[b]{2}{*}{ Pictures } & High Criticality & 0.96 & 0.10 \\
\hline & & Low Criticality & 0.92 & 0.20 \\
\hline & \multirow[b]{2}{*}{ Text } & High Criticality & 0.92 & 0.09 \\
\hline & & Low Criticality & 0.93 & 0.10 \\
\hline
\end{tabular}

A significant three-way interaction was observed for the variables modality, criticality, and experience; $F(1,38)=4.59, p=0.03, \eta^{2}=.55$, observed power $=0.671$. Simple effects tests showed a significant difference between military personnel $(M=3.97, S E=$ $0.01)$ and students $(M=3.58, S E=0.01)$ when asked to collect pictorial targets in the high criticality condition, $t(1,38)=10.65, p=<.001$. Military personnel also collected more targets presented in text in the high criticality condition $(M=3.85, S E=0.01)$ than students in the high criticality condition $(M=3.72, S E=0.01) ; t(1,38)=3.98, p=0.04$. As hypothesized, military and students both accurately collected more pictorial targets in the high criticality condition than the low criticality condition. Additionally, both samples collected more pictorial targets in the highly critical condition than in the low criticality condition. Interestingly, more targets presented with textual labels were correctly collected in the low criticality condition for both military and student samples. 
More overall pictorial targets were collected by military personnel than students; $(M=$ 7.98, $S E=0.01),(M=7.78 ; S E=0.01)$ respectively; however the simple effects test showed no significant difference. More targets were also collected in the high criticality condition by military and student participants; however, this simple effect was not significant. Plots depicting the data average values can be found in Figures 2 and 3.

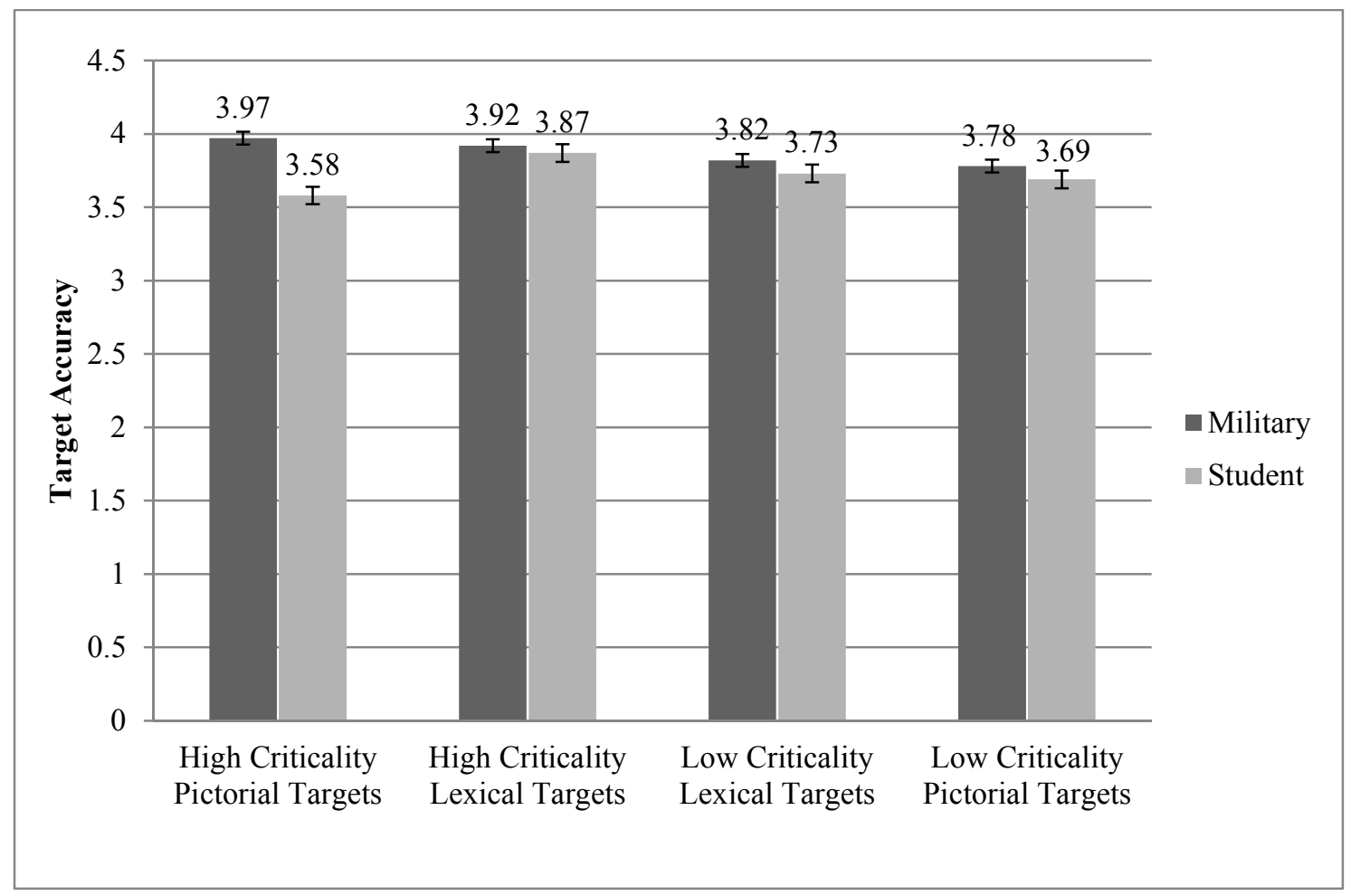

Figure 2. Target retrieval accuracy as a function of task criticality, information modality, and participant background. 


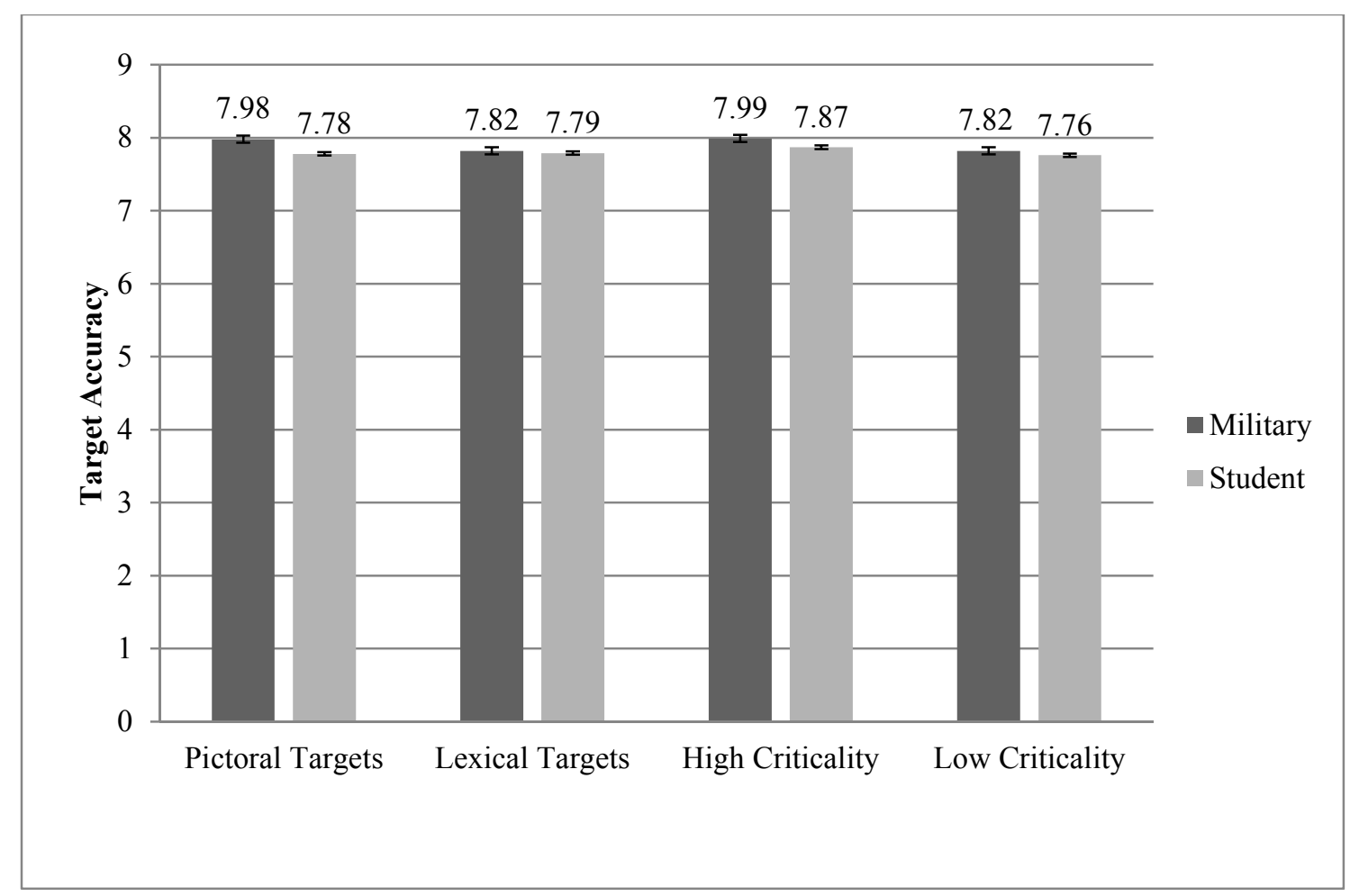

Figure 3. Mean target location rate as a function of information modality, participant background, and task criticality.

The results of the ANOVA also indicated that the main effect for experience approached significance; $F(1,38)=2.56, p=0.059, \eta^{2}=0.78$. This finding for target accuracy relating to experience may be due to the lack of substantial mean differences across population, target modality, and criticality. No additional significant effects were observed for target accuracy $(p>0.05)$.

\section{Acquisition Time}

Acquisition time calculations were averaged across both modality and criticality conditions to yield an average acquisition time for text-presented instructions, imagepresented instructions, and each criticality condition. Levene's tests were used to ensure adequate homogeneity of variance, and Mauchly's test of sphericity indicated that the 
assumption of sphericity was not violated. The ANOVA results for acquisition time are presented in Table 5 .

Table 5

Analysis of Variance Results for Acquisition Time

\begin{tabular}{lcccccc}
\hline \multicolumn{1}{c}{ Source } & SS & df & MS & $F$ & $p$ & partial $\eta^{2}$ \\
\hline Between Subjects & & & & & & \\
Experience (E) & 11.26 & 1 & 11.26 & 4.23 & 0.17 & .05 \\
Error & 3.11 & 38 & 0.06 & & & \\
& & & & & & \\
\hline Within Subjects & & & & & & \\
Criticality (C) & 24.01 & 1 & 24.01 & 36.15 & 0.00 & 0.84 \\
C x E & 3.62 & 1 & 3.62 & 0.91 & 0.35 & 0.02 \\
Error & 13.62 & 38 & 0.08 & & & \\
Modality (M) & 5.01 & 1 & 5.01 & 7.11 & 0.01 & 0.75 \\
M x E & 1.15 & 1 & 1.15 & 1.17 & 0.19 & 0.10 \\
Error & 9.22 & 38 & 0.03 & & & \\
C X M & 2.86 & 1 & 2.86 & 7.94 & 0.03 & 0.81 \\
C x M x E & 0.92 & 1 & 0.92 & 2.21 & 0.26 & 0.13 \\
Error & 16.61 & 38 & 0.01 & & & \\
\hline
\end{tabular}

Descriptive statistics were calculated for acquisition time and are presented in Table 6.

Table 6

Means and Standard Deviations for Acquisition Time

\begin{tabular}{cclcc}
\hline Experience & Modality & Criticality & $M$ & $S D$ \\
\hline \multirow{3}{*}{ Military } & \multirow{2}{*}{ Pictures } & High Criticality & 153.31 & 54.39 \\
& & Low Criticality & 172.94 & 41.37 \\
\cline { 2 - 5 } & \multirow{2}{*}{ Text } & High Criticality & 165.87 & 55.91 \\
& & Low Criticality & 162.39 & 42.44 \\
\hline \multirow{3}{*}{ Student } & \multirow{2}{*}{ Pictures } & High Criticality & 158.06 & 55.48 \\
& \multirow{2}{*}{ Text } & Low Criticality & 173.21 & 41.90 \\
\cline { 3 - 5 } & \multirow{2}{*}{ Tex } & High Criticality & 160.35 & 54.04 \\
& & Low Criticality & 175.50 & 44.68 \\
\hline
\end{tabular}


A significant main effect was observed for the variable of criticality; $F(1,38)=20.41, p$ $=<.001, \eta^{2}=.84$, observed power $=.723$. A significant main effect was also observed for the modality variable; $F(1,38)=7.11, p=.01, \eta^{2}=.75$, observed power $=.668$. As hypothesized, participants collected pictorial targets faster than targets presented with textual descriptions. Participants also collected both target types faster in the high criticality condition.

For the hypothesis that predicted an interaction between modality and criticality, a significant two-way interaction was observed; $F(1,38)=7.94, p=0.03, \eta^{2}=0.81$, observed power $=0.623$. Means showed that military personnel took longer to locate textual targets than pictorial ones in the low criticality condition, $(M=172.94, S E=$ 3.85); $(M=162.39, S E=6.29)$ respectively. Students also took longer to locate textual targets than pictorial targets in the low criticality condition; $(M=175.50, S E=5.96) ;(M=$ 173.21, $S E=4.97$ respectively). Interestingly, military participants took longer to locate textual targets in the high criticality condition than in the low criticality condition; $(M=$ $165.87, S E=6.01) ;(M=162.39, S E=3.72$ respectively $)$. A plot displaying this interaction can be seen in Figure 4. No other significant main effects or interactions were observed for acquisition time. 


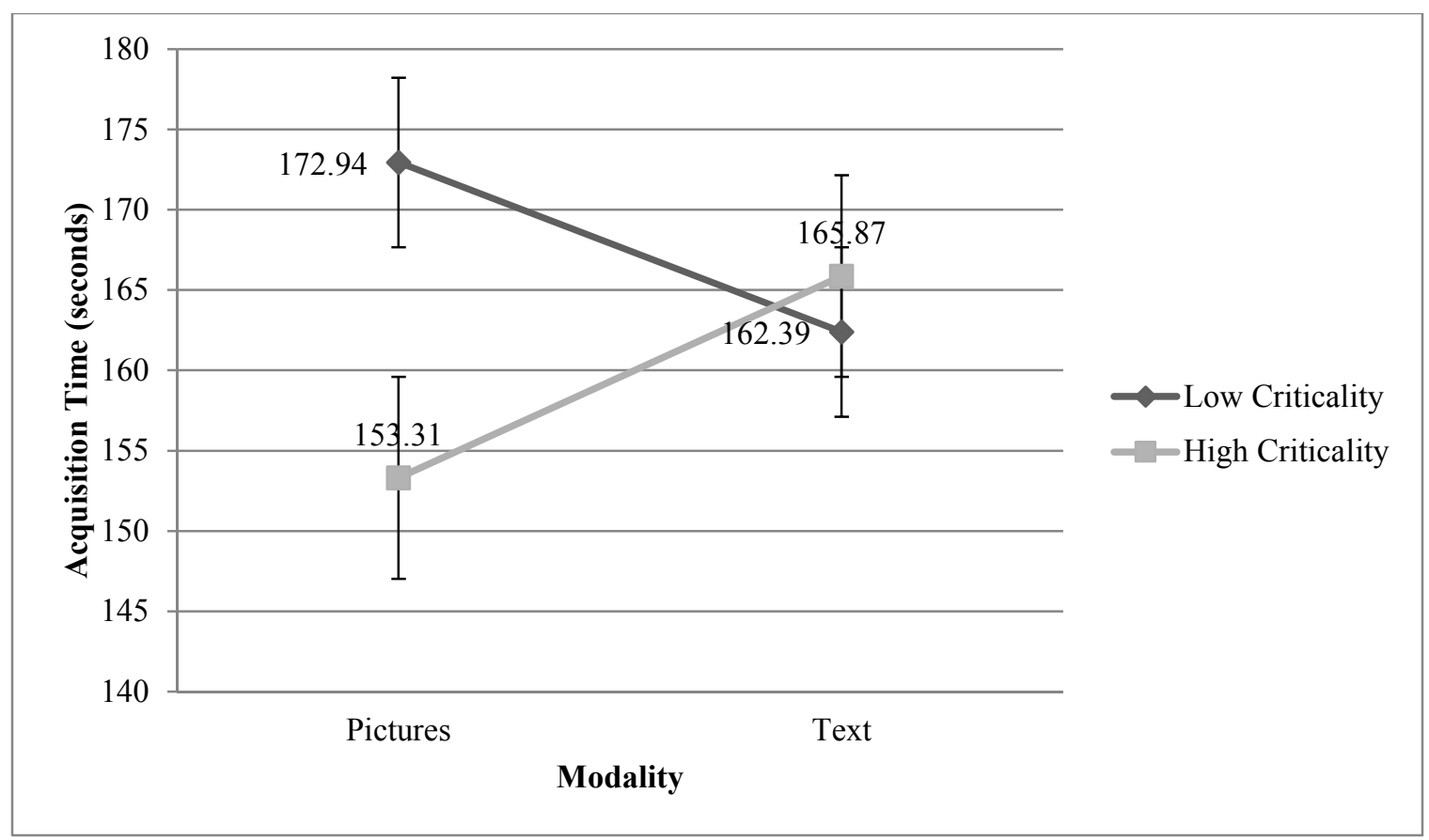

Figure 4. Target acquisition time for each criticality condition as a function of target modality presentation.

\section{Errors}

The number and type of errors committed were noted by the researcher as participants navigated through the scenario conditions. This data were then summed and analyzed respective to criticality condition and target modality. As a reminder, there were four types of errors a participant could commit: returning to the incorrect starting position after locating a target (Type 1), locating an incorrect target (Type 2), referencing irrelevant scenario icons or displays (Type 3), and failing to locate a target (Type 4). In general, fewer overall errors were made in both conditions than initially expected. Homogeneity of variance was assessed using Levene's tests; the results indicated that homogeneity of variance was adequate. Mauchly's test of sphericity indicated that the assumption of sphericity was not violated. 
The ANOVA results are presented in Table 7.

Table 7

Analysis of Variance for Errors of Commission

\begin{tabular}{lcccccc}
\hline \multicolumn{1}{c}{ Source } & SS & df & MS & $F$ & $p$ & partial $\eta^{2}$ \\
\hline Between Subjects & & & & & & \\
Experience (E) & 1.25 & 1 & 1.25 & 1.34 & 0.26 & 0.20 \\
Error & 35.49 & 38 & 0.93 & & & \\
& & & & & & \\
\hline Within Subjects & & & & & & \\
Criticality (C) & 12.80 & 1 & 12.80 & 27.58 & 0.00 & 0.80 \\
C x E & 0.31 & 1 & 0.31 & 0.67 & 0.42 & 0.13 \\
Error & 17.64 & 38 & 0.46 & & & \\
Modality ( M ) & 2.45 & 1 & 2.45 & 5.42 & 0.03 & 0.62 \\
M x E & 0.11 & 1 & 0.11 & 0.25 & 0.62 & 0.08 \\
Error & 17.19 & 38 & 0.45 & & & \\
C X M & 2.45 & 1 & 2.45 & 4.26 & 0.14 & 0.71 \\
C x M x E & 8.45 & 1 & 8.45 & 7.27 & 0.01 & 0.75 \\
Error & 44.19 & 38 & 1.16 & & & \\
\hline
\end{tabular}

A significant three-way interaction was observed for modality, criticality, and experience; $F(1,38)=8.45, p=0.01, \eta^{2}=0.75$, observed power $=0.748$. Simple effects tests showed that military personnel made more errors searching for lexical targets $(M=0.55$, $S E=0.89)$ than students $(M=0.20, S E=0.41)$ in the high criticality condition. Military personnel also made more errors searching for pictorial targets in the high criticality condition $(M=0.10, S E=0.31)$ than students $(M=0.05, S E=0.22)$. In the low criticality condition, military personnel also made more errors searching for lexical targets $(M=0.75, S E=0.91)$ compared with pictorial targets $(M=0.45, S E=0.76)$. Students searching for lexical targets also made more errors than military participants during navigation when searching for pictorial targets; $(M=0.45, S E=1.30),(M=0.40$, 
$S E=0.82)$ respectively. Interestingly, military participants made more errors than students in both conditions; however, the mean differences are smaller between the two populations in the low criticality condition. Significant main effects were observed for the variables modality and criticality; $F(1,38)=5.42, p=0.03, \eta^{2}=0.62$, observed power $=0.821 ;$ and $F(1,38)=27.58, p=<.001, \eta^{2}=0.80$, observed power $=0.605$, respectively. For modality, more errors were committed with textual targets. In line with the stated hypothesis, fewer overall errors were committed in the high criticality condition.

\section{Subjective Workload}

In line with the stated hypothesis, military participants experienced slightly higher subjective workload in almost all areas in the high criticality condition compared with the low criticality condition; however, other performance data did not suffer due to the increased workload. Interestingly, student participants experienced higher subjective workload in all areas (with the exception of mental workload) in the low criticality condition. Military participants also experienced higher subjective workload on all subscales (less physical demand) in the high criticality condition than their student counterparts. For example, for the mental demand subscale, military participants experienced a mean of 69.20 in the high criticality condition, whereas students experienced a mean of 63.00. These results can be seen in Figure 5 . 


\begin{tabular}{|c|c|c|c|c|}
\hline \multirow{9}{*}{ 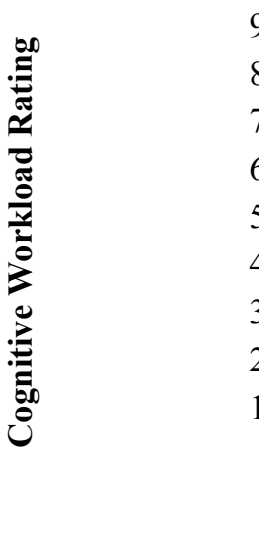 } & & & & \\
\hline & & & & \\
\hline & & & & \\
\hline & & & & \\
\hline & & & & \\
\hline & & & & \\
\hline & & , & & \\
\hline & & & & \\
\hline & $\begin{array}{l}\text { Military Low } \\
\text { Criticality }\end{array}$ & $\begin{array}{l}\text { Military High } \\
\text { Criticality }\end{array}$ & $\begin{array}{l}\text { Student Low } \\
\text { Criticality }\end{array}$ & $\begin{array}{l}\text { Student High } \\
\text { Criticality }\end{array}$ \\
\hline Mental & 68.5 & 69.2 & 61.5 & 63 \\
\hline Physical & 27.5 & 13.5 & 30.1 & 30.3 \\
\hline Temporal & 69.5 & 66 & 61 & 35 \\
\hline Own Performance & 56.5 & 59.9 & 52 & 46 \\
\hline Effort & 71.5 & 77.8 & 53 & 39 \\
\hline Frustration & 65 & 67.5 & 63.5 & 44 \\
\hline
\end{tabular}

Figure 5. Cognitive workload means for each subscale relative to population and criticality level. 


\section{DISCUSSION}

The purpose of this research was to determine whether pictorial representations evoke faster and more accurate search performance than textual representations during a critical object search scenario. Especially important to warfighters and other critical operators who put themselves at risk of physical harm, the modality in which information is presented may affect overall performance. In accordance with the hypotheses proposed, it seems that modality affects overall task performance, and pictorial representations seem to be a better means of communicating information for instruction in a critical scenario.

It was hypothesized that participants in this study would collect pictorial targets faster than textual targets. Students and military participants collected pictorial targets faster than textual targets in both experimental conditions, and both populations collected pictorial targets faster in the highly critical scenario. The Pictorial Superiority Effect posits that images are better forms of instruction for short-term memory recall tasks (Bowen \& Standing, 1976; Mcbride \& Dosher, 2002; Paivio \& Csapo, 1973; Peloquin, 1979). It was unclear whether this assumption would translate to critical tasks or tasks completed in a virtual environment. As suggested by the Pictorial Superiority Effect and dual-coding theory, pictorial target representations were significantly better for participant accuracy performance than lexical targets. This is likely because pictorial target representations required fewer cognitive resources to process, leading to better cognitive processing, as both theories posit. Targets represented with pictorial images were found significantly faster than textual targets, lending additional credence to the Pictorial Superiority Effect. From the findings of this research, it can be concluded that 
the Pictorial Superiority Effect applies to the virtual environment and short-term critical search task used in this research.

It was also expected that more overall targets would be located in the highly critical condition, and that more pictorial targets would be collected in the highly critical condition. These hypotheses were supported, as both populations collected more overall targets, and specifically more pictorial targets, in the highly critical condition compared with the low criticality condition. These results support the findings of Kliegel et al. (2004), as it seems that performance increased when participants considered the task more important. Target accuracy results also support the findings of Harris and Hancock (2005): participants' accuracy levels increased after exposure to a critical scenario.

Previous research (Callister et al., 1999; Elsmore et al., 1992; Slaven \& Windle, 1999) posited that critical tasks do not impair cognitive ability, and may actually increase it for a short time. From the current findings, it appears that cognitive ability was not impaired when participants were subjected to a critical task. Bliss et al. (2013) and Hanson et al. (2014) demonstrated that manipulating task criticality influences operator performance. These findings were also replicated, as operator accuracy significantly increased when participants were exposed to the highly critical search task. From the Pictorial Superiority Effect and dual-coding theory, pictorial images are encoded and processed more efficiently than their textual counterparts. Faster and more efficiently encoded information can also be retrieved more efficiently, allowing an operator to react faster during a critical scenario.

Unexpectedly, both participant populations collected more lexical targets in the low criticality condition than in the high criticality condition. Nelson et al. (1976) suggested 
that the Pictorial Superiority Effect exists only in comparisons of objects with low schematic similarity. Comparisons with high schematic similarity showed participants more likely to recall textual information. The combination of low task criticality and high target schematic similarity may have led to this result, as participants may have felt a lower pressure to perform and dedicated more resources to finding the textual targets. It is also possible that participants took more time to process lexical targets in the low criticality condition because they did not feel as time-pressured.

Fewer overall errors were expected in the highly critical task because the Critical Decision Method (Klein et al., 1989) assumes participants will rely on their most efficient cognitive resources to complete a critical task. This hypothesis was generally supported, as participants from both samples committed fewer errors in the highly critical scenario. From the findings of Harris and Hancock (2005), it was expected that military participants would suffer higher cognitive workload than student participants in the highly critical scenario. Harris and Hancock (2005) demonstrated that prior training may affect the way that warfighters process critical information (though overall performance in the critical task does not suffer). The researchers found that military participants exposed to a critical scenario experienced better cognitive performance for a short time; however, it was subject to rapid decay if exposed to prolonged stress. The current study found similar results; military participants experienced higher cognitive workload in most areas compared to students in the highly critical scenario, though their overall performance in the task did not suffer. This finding illustrates that experience and training with critical scenarios influences the way they are mentally processed, though performance is not necessarily affected. 
An interaction was found between target modality and criticality for acquisition time. During high criticality conditions, the time it took to locate pictorial targets decreased. During low criticality conditions, the time it took to locate textual targets increased. This finding provides support for dual-coding theory (Buckner et al., 2000; Paivio, 1971; Schnotz, 2001; Schnotz, 2002; Schnotz \& Bannert, 1999; Standing \& Smith, 1975) as results suggest pictorial information is encoded by two cognitive mechanisms instead of one. This explains why pictorial representations are accessed easier than textual models during a critical scenario. By not necessarily having to form and later access a complex mental model resulting from encoding abstract textual information, an individual is able to execute a task given in pictorial instructions more efficiently and quickly. However, these results suggest that when a scenario is not highly critical, participants may have still been cognitively forming abstract mental models.

The findings from this study suggest that individuals should be presented with pictorial images as much as possible, especially during high-criticality situations. This specifically applies to warfighters on the battlefield, when required to use physical intelligence information. From Krupenia et al. (2012), warfighters are likely to use only one modality of information when executing a task or mission. If the stimuli they are presented with includes a pictorial representation of the mission, efficiency and acquisition time are likely to improve. Additionally, pictorial information may decrease cognitive resource demand, freeing cognitive resources for other tasks. Finally, pictorial information may reduce the number of errors committed on the battlefield, or in any arena within which operators are potentially faced with critical scenarios. 
While this study provided evidence that pictorial information should be used whenever possible in a critical scenario, some limitations should be addressed. The majority of the participants used in this study were male; it is possible that females react to critical scenarios more efficiently using a different modality of presentation. Future research should thoroughly study gender differences. Additionally, the critical scenario used in this experiment was created using a virtual platform. Future research should study the criticality variable using real-world experimental scenarios.

Future research should also adapt this paradigm to compare military participants from different military branches. It is possible mission training (type and extent) could have an effect on modality dependence, and different military branches receive dramatically different forms of training. Additionally, the Pictorial Superiority Effect should be tested in other virtual environments to determine if results are consistent across different virtual platform. 


\section{REFERENCES}

Alderman, N., Burgess, P. W. , Knight, C. , \& Henman, C. (2003). Ecological validity of a simplified version of the multiple errands shopping test. Journal of the International Neuropsychological Society, 14, 31-44.

Azizian, A., Freitas, A. L., Watson, T. D., \& Squires, N. K. (2006). Electrophysiological correlates of categorization: P300 amplitude as index of target similarity. Biological Psychology, 71, 278-288.

Beagle, J. M. (2009). Pictures versus text: Modality effects across three levels of learning and study time. Dissertations Abstracts International, 71, 1520.

Bliss, J. P., \& McAbee, P. E. (1995). Alarm responses in a dual-task paradigm as a function of primary task criticality. Proceedings of the Human Factors and Ergonomics Society $39^{\text {th }}$ Annual Meeting, USA, 2, 1395-1399.

Bliss, J. P., Harden, J. W., \& Dischinger, C. D. (2013). Task shedding and control performance as a function of perceived automation reliability and time pressure. Proceedings of the Human Factors and Ergonomics Society57th Annual Meeting. San Diego, CA: Human Factors and Ergonomics Society.

Bowen, C., \& Standing, L. (1976.) Imagery and meaningfulness ratings of sentences: Reliability and relationship to learning. Perceptual and Motor Skills, 42, 479-483. doi: 10.2466/pms.1976.42.2.479

Buckner, R. L., Logan, J., Donaldson, D. I., \& Wheeler, M. E. (2000). Cognitive neuroscience of episodic memory encoding. Acta Psychologica, 105, 127-139. 
Callister, J. D., Percival, G. L. \& Retzlaff, P. D. (1999). Stress and fatigue during aircrew survival training. Proceedings of the International Symposium on Aviation Psychology, 10, 843-847.

Carvalho, P. V., dos Santos, I. L., Vidal, M. C. (2005). Nuclear power plant shift supervisor's decision making during microincidents. International Journal of Industrial Ergonomics, 35(7), 619-644.

Chancey, E. T., \& Bliss, J. P. (2012) Unreliable information in infantry situation awareness: Improvement through game-based training. Simulation and Gaming, 43(5), 581-599. doi: 10.1177/1046878112439452

Chee, M. W., Buckner, R. L., Savoy, R. L. (1998). Right hemisphere language in a neurologically normal dextral: A fMRI study. Neuroreport: An International Journal for the Rapid Communication of Research in Neuroscience, 9, 34993502. doi: 10.1097/00001756-199810260-00030

Cohen, J. (1992). A Power Primer. Quantitative Methods in Psychology, 112(1), 155-159.

Einstein, G. O., \& McDanial, M. A. (1990). Normal aging and prospective memory. Journal of Experimental Psychology: Learning, Memory, and Cognition, 16(4), $717-726$.

Eitel, A., Scheiter, K., Schuler, A. , Nystrom, M. , \& Holmqvist, K. (2013). How a picture facilitates the process of learning from text: Evidence for scaffolding. Learning and Instruction, 28, 48-63.

Elsmore, T. F., Naitoh, P. , \& Linnville, S. (1992). Performance assessment in sustained operations. Naval Health Research Center. 
Glenberg, A. M., \& Robertson, D. A. (1999). Indexical understanding of instructions. Discourse Processes, 28, 1-26. doi: 10.1080/01638539909545067

Hanson, J. A., Bliss, J. P., Harden, J. W., \& Papelis, Y. The effects of reliability and criticality on an IED interrogation task. Proceedings of the Human Factors and Ergonomics Society58th Annual Meeting. Chicago, IL: Human Factors and Ergonomics Society (submitted).

Harris, W. C. \& Hancock, P. A. (2005). Information processing changes following extended stress. Military Psychology, 17(2), 115-128.

Hart, S. G. (1988). Development of NASA-TLX (Task Load Index): Results of Empirical and Theoretical Research. Advances in Psychology, 52, 139-183.

Kintsch, W., \& van Dijk, T. A. (1978). Toward a model of text comprehension and production. Psychological Review, 85, 363-394. doi: 10.1037/0033$295 X .85 .5 .363$

Klein, G. A., Calderwood, R., \& MacGregor, D. (1989). Critical decision method for eliciting knowledge. Transactions on Systems, Man, \& Cybernetics, 19(3) 462472. doi:10.1109/21.31053

Kliegel, M. , Martin, M. , McDaniel, M.A., Einstein, G.O. (2004). Importance effects on performance in event- based prospective memory tasks. Memory, 12(5) 553-561.

Knight, C. Alderman, N., \& Burgess, P. W. (2002). Development of a simplified version of the multiple errands test for use in hospital settings. Neuropsychological Rehabilitation, 12(3), 231-255. 
Krupenia, S. S., Aguero, C., \& Nieuwenhuis, K. (2012). The value of different media types to support command and control situation awareness. Proceedings of the $9^{\text {th }}$ International ISCRAM Conference, Canada.

Krupenia, S. S., Cuizinaud, M. , Muller, T. , \& van der Hulst, A. (2012). Collecting battlefield information using a multimodal personal digital assistant. Human Factors of Systems and Technologies, 327-240.

Maxwell, S. E. \& Delaney, H. D. (2004). Designs with random or nested factors. Designing Experiments and Analyzing Data. 469-521. New Jersey: Lawrence Erlbaum Associates Inc.

Mayer, R. E., \& Sims, V. K. (1994). For whom is a picture worth a thousand words? Extensions of a dual-coding theory of multimedia learning. Journal of Educational Psychology, 86(3), 389-401.

McBride, D. M. , \& Dosher, B. A. (2002). A comparison of conscious and automatic memory processes for picture and word stimuli: A process dissociation analysis. Consciousness and Cognition, 11, 423-460.

McDaniel, M. A., Einstein, G.O. (1993). The important of cue familiarity and cue distinctiveness in prospective memory. Memory,1(1), 23-41.

Mioni, G., Stablum, F., McClintock, S. M., \& Cantagallo, A. (2012). Time based prospective memory in severe traumatic brain injury patients: The involvement of executive functions and time perception. Journal of the International Neuropsychological Society, 18, 697-705. 
Morrow, D. G., Greenspan, S. L., \& Bower, G. H. (1987). Accessibility and situation models in narrative comprehension. Journal of Memory and Language, 26, $165-$ 187. doi: 10.1016/0749-596X(87)90122-7

Nalu, A. (2011). Comics as a cognitive training medium for expert decision making. (Doctoral dissertation). Old Dominion University, Norfolk.

Nelson, D. L. (1979). Remembering pictures and words: Appearance, significance, and name. Levels of Processing in Human Memory (pp. 45-76). Hillsdale, NJ: Erlbaum.

Nelson, D. L., Reed, V. S., \& McEvoy, C. L. (1977). Learning to order pictures and words: A model of sensory and semantic encoding. Journal of Experimental Psychology: Human Learning and Memory, 3, 485-497.

Nelson, D. L., Reed, V. S., \& Walling, J. R. (1976). Pictorial Superiority Effect. Journal of Experimental Psychology, 2, 523-528. doi: 10.1037/0278-7393.2.5.52

Nigro, G., Cicoqna, P. C., D’Olimpio, F., \& Cosenza, M. (2012). The role of visual perceptual style and personality disorder traits in event-based prospective memory. Personality and Individual Differences, Vol 53, 912-916.

Nyberg, L., Persson, J., Habib, R., Tulving, E., Mcintosh, A.R., Cabeza, R., \& Houle, S. (2000). Large scale neurocognitive networks underlying episodic memory. Journal of Cognitive Neuroscience, 12, 163-173. doi: 10.1162/089892900561805

Paivio, A. (1971). Imagery and verbal processes. New York: Holt, Rinehart, and Winston, Inc.

Paivio, A., \& Csapo, K. (1973). Picture superiority in free recall: Imagery or dual coding? Cognitive Psychology, 5, 176-206. doi: 10.1016/0010-0285(73)90032-7 
Paivio, A. (1991). Dual coding theory: Retrospect and current status. Canadian Journal of Psychology, 45, 255-287.

Peloquin, P. V. (1979). Pictorial superiority: Imagery or dual coding? Paivio \& Csapo, 1973, Revisited. Dissertation Abstracts International, 39, 5418-5419.

Rand, D., Soraya, Bashu-Abu Rukan, Weiss, P. L., \& Katz, N. (2009) Validation of the Virtual MET as an assessment tool for executive functions. Neuropsychological Rehabilitation, 19, 583-602.

Schnotz, W. (1993). On the relation between dual coding and mental models in graphics comprehension. Learning and Instruction, 3, 247-249.

Schnotz, W., \& Bannert, M. (1999). Support and interference effects in learning from multiple representations. Cognitive Science, 6, 149-168.

Schnotz, W. (2001). Sign systems, technologies, and the acquisition of knowledge. Multimedia Learning- Cognitive and Instructional Issues, 18, 9-29.

Schnotz, W. (2010). Reanalyzing the expertise reversal effect. Instructional Science, 38, 315-323. doi: 10.1007/s11251-009-9104-y

Shallice, T., \& Burgess, P. W. (1991). Deficits in strategy application following frontal lobe damage in man. Brain, 114, 727-741.

Shallice, T., \& Burgess, P. W. (1991) Can the neuropsychological case-study approach be applied to schizophrenia? Psychological Medicine, 21, 661-673.

Standing, L., \& Smith, P. (1975). Verbal-pictorial transformations in recognition memory. Canadian Journal of Psychology, 29, 316-326.

Slaven, G. M., \& Windle, C. M. (1999). Cognitive performance over 7 days in a distressed submarine. Aviation, Space, and Environmental Medicine, 70, 604-608. 
Van Dijk, T. A., \& Kintsch, W. (1983). Strategies of Discourse Comprehension. Academic Press, New York.

Van Hooijdonk, C., \& Krahmer, E. (2008). Information modalities for procedural instructions. The influence of text, pictures, and film clips on learning and executing RSI exercises. Transactions on Professional Communication, 51,50-62. doi: 10.1109/TPC.2007.2000054

Weaver, C. A., Mannes, S., \& Fletcher, C. R. (1995). Discourse Comprehension, Erlbaum, Hillsdale, NJ.

Wheeler, M. E., Petersen, S. E., \& Buckner, R. L. (2000). Memory's echo: Vivid remembering reactivates sensory-specific cortex. Proceedings of the National Academy of Sciences, 97, 11125-11129.

Wickens, C. D. (1996). Designing for stress. Stress and human performance, 279-295.

Wickens, C. D. (1988). Codes and modalities in multiple resources: A success and a qualification. Human Factors, 30, 559-616.

Wickens, C. D. (2002). Multiple resources and performance prediction. Theoretical Issues in Ergonomics Science, 3, 159-177.

Wickens, C. D. (2007). How many resources and how to identify them? Human Factors, $49,53-56$.

Wickens, C. D. (2008). Mulitple Resources and Mental Workload. Human Factors: The Journal of the Human Factors and Ergonimics Society, 50, 449-454.

Wickens, C. D. (2010). Multiple resources and perfprmance prediction. Theoretical Issues in Ergonomics Science, 3, 159-177. 
Xiao, Y. M., Wang, Z. M., Wang, M. Z., \& Lan, Y. J. (2005). The appraisal of relaibility and validity of subjective workload assessment technique and NASA-TLX load index. Chinese Journal of Industrial Hygiene and Occupational diseases, 23, 178181.

Zatorre, R. J., Halpern, A. R., Perry, D. W., Meyer, E. , \& Evans, A. C. (1996). Hearing in the mind's ear: A PET investigation and musical imagery and perception. Journal of Cognitive Neuroscience, 8, 29-46.

Zwaan, R. A., \& Radvansky, G. A. (1998). Situation models in language comprehension and memory. Psychological Bulletin, 123, 162-185. 


\section{APPENDIX A \\ OLD DOMINION UNIVERSITY INFORMED CONSENT FORM}

\section{INFORMED CONSENT DOCUMENT}

The purposes of this form are to give you information that may affect your decision whether to say YES or NO to participation in this research, and to record the consent of those who say YES.

TITLE OF RESEARCH: Battlefield Behavior Using Different Target Modalities

\section{RESEARCHERS:}

James P. Bliss, Ph.D., Professor, Responsible Project Investigator, College of Sciences, Psychology Department

Julie A. Hanson, graduate student, College of Sciences, Psychology Department.

DESCRIPTION OF RESEARCH STUDY: It is unclear whether pictures or text are more useful in a battlefield search task. Military training often provides warfighters with lengthy instruction manuals for completing tasks that may be out of the ordinary, but it is questionable whether these manuals provide the best form of instruction in a scenario that requires immediate response. Research has suggested pictures may be more useful for a short-term memory search task however further investigation is needed.

Forty participants will be tested in this experiment. Those who agree to be tested will complete several background information forms. Following this, you will be asked to perform a familiarization session for a search task in a virtual environment. After training, you will be asked to perform the computer-based search task with instruction and feedback from the researcher. Following the experimental session, you will be asked to complete a questionnaire assessing your mental workload. You will then be debriefed and dismissed. The entire experiment should last approximately 2 hours.

\section{EXCLUSIONARY CRITERIA:}

To participate, you must be over the age of 18 . You must not have any visual color deficiency, and normal or corrected-to-normal vision. You must not have a history of traumatic brain disorder or post -traumatic stress disorder.

\section{RISKS AND BENEFITS:}

RISKS: If you decide to participate in this study, you may face a risk of eyestrain similar to the eyestrain experienced during normal computer usage. The researcher tried to reduce this risk by limiting the experimental participation time to less than one hour. If you have a history of combat exposure (deployment), it is possible that you may experience some task- related stress. The research tried to reduce this risk by limiting participation to individuals who have never experienced a Traumatic Brain Injury (TBI) or Post-Traumatic Stress Disorder (PTSD). As with any research, there is some possibility that you may be subject to risks that have not been identified.

BENEFITS: There are no direct benefits for participation in this study. However, you may learn valuable information about how research is conducted.

\section{COSTS AND PAYMENTS:}

The researchers want your decision about participating in this study to be absolutely voluntary.

STUDENTS: If you are a student, the main benefit to you for participating in this study is the extra credit or course credit points that you will earn for your class. If you decide to participate in this study, you will receive 1 Psychology Department research credit, which may be applied to course requirements or extra credit in certain Psychology courses. Equivalent credits may be obtained in other ways. You do not have to participate in this study, or any Psychology Department study, to obtain this credit. In addition, you will be given a five dollar Starbucks gift card. 
NON-STUDENTS: If you decide to participate in this study, you will receive twenty dollars in financial compensation upon completing the study.

\section{CONFIDENTIALITY:}

Your participation is completely confidential. The researcher will remove all identifiers from the information. The results of this study may be used in reports, presentations, and publications; but the researcher will not identify you individually in such publications.

\section{WITHDRAWAL PRIVILEGE:}

It is OK for you to say NO. Even if you say YES now, you are free to say NO later, and walk away or withdraw from the study -- at any time. Your decision will neither affect your relationship with Old Dominion University, nor cause a loss of benefits to which you might otherwise be entitled. The researchers reserve the right to withdraw your participation in this study, at any time, if they observe potential problems with your continued participation.

You are able to terminate your participation in this study at any time with no penalty.

\section{COMPENSATION FOR ILLNESS AND INJURY:}

If you agree to participate, then your consent in this document does not waive any of your legal rights. However, in the event of harm, injury, or illness arising from this study, neither Old Dominion University nor the researchers are able to give you any money, insurance coverage, free medical care, or any other compensation for such injury. In the event that you suffer injury as a result of participation in any research project, you may contact Dr. James P. Bliss at 757-683-4051, Dr. George Maihafer (IRB Chair) at 757-6834520 , or the ODU Office of Research, 757-683-3460.

\section{VOLUNTARY CONSENT:}

By signing this form, you are saying several things. You are saying that you have read this form or have had it read to you, that you are satisfied that you understand this form, the research study, and its risks and benefits. The researchers should have answered any questions you may have had about the research. If you have any questions later on, please contact the researcher at the number above.

If at any time you feel pressured to participate, or if you have any questions about your rights or this form, then you should call Dr. George Maihafer (IRB Chair) from the Old Dominion University Office of Research, 757-683-4520, or the ODU Office of Research, 757-683-3460.

By signing below, you are telling the researcher YES, that you agree to participate in this study. The researcher should give you a copy of this form for your records.

Participant's Name

Investigator's Name
Participant's Signature

Investigator's Signature

\section{Date}

Date 
APPENDIX B

DEMOGRAPHIC QUESTIONNAIRE

\section{Participant ID:}

1.) What is your age in years?

2.) What is your sex? (Circle One)

- Male

- Female

3.) How many hours per week do you spend playing video games?

4.) Do you have any visual color deficiency (e.g. colorblindness)? (Circle One)

- Yes

- No

5.) Do you have normal or corrected-to-normal vision? (Circle One)

- Yes

- No 


\section{APPENDIX C}

\section{MILITARY BACKGROUND QUESTIONNAIRE}

\section{(If you have never served in the military, please move on to the next form)}

\section{Participant ID:}

1.) Are you currently active duty? (Circle One)
a. Yes
b. No

2.) Which branch are/ were you affiliated with?
a. Army
b. Marines
c. Air Force
d. Navy
e. Coast Guard
f. Reservist (please indicate branch)

3.) What is/ was your time in service?

4.) What is/ was your rank?

5.) What is/ was your grade?

6.) What is/ was your time in grade?

7.) What is/ was your MOS?

8.) Have you deployed?
a. Yes
b. No

9.) If you have deployed more than once, please indicate the number of deployments:

10.) Where were you deployed? (Circle all that apply)
a. Iraq
b.Afghanistan
c. Kuwait
d. Bosnia
e. Vietnam
f. Korea
g. Other: 
11.) When were you deployed (month and year)?

12.) How long was each deployment (in months)?

13.) What was your rank/ grade at the time of each deployment?

14.) What was your MOS at the time of each deployment?

15.) Were you ever attached to a different unit (other than your MOS) when you deployed?

a. Yes

b. No

If yes, please explain:

16.) Were you ever involved in direct combat?

a. Yes

b. No

If yes, please (briefly)

explain:

17.) Have you ever experienced the effects or been diagnosed with Post-Traumatic Stress Disorder?
a. Yes

b. No 


\section{APPENDIX D \\ BRAIN FUNCTION QUESTIONNAIRE}

\section{Participant ID:}

- Have you ever been diagnosed with a traumatic brain injury, brain injury, or concussion?

1.) Yes

2.) No

- Are you currently experiencing any symptoms that you think may be related to a head injury?

1.) Yes

2.) No

If you do not have a history of military service, please write N/A and alert the researcher that you are finished.

- Did an injury received while deployed result in any of the following? (Check all that apply):

1.) Being dazed, confused, or "seeing stars"

2.) Not remembering the injury

3.) Losing consciousness

4.) Having symptoms of a concussion afterward (such as headache, extreme drowsiness, dizziness, etc.)

5.) Head Injury

6.) NONE 


\section{APPENDIX E \\ GENERAL INSTRUCTIONS}

(Read by researcher)

"You will be participating in a computer-based target location task. Participating in this experiment will be similar to playing a computer game, but you will have to pay attention to my instructions throughout the task, and I will also be recording some of your actions. You will control a Soldier in the United States Army and you will be navigating through an environment that has been made to simulate a marketplace in Iraq. I will now give you the opportunity to familiarize yourself with the marketplace. You will have six minutes to get used to the controls and navigate through the marketplace; while doing so, pay special attention to the vendors and the items that are for sale. Only pay attention to the items that have prices listed next to them. After six minutes, I will ask you to locate some items, and the experimental session will begin when you are able to locate two items correctly."

"Now I would like you to practice locating items. First, I would like for you to find the red and white sign with the camel on it; it looks similar to a yield sign."

"Now I would like for you to locate a vendor that is selling watermelon for $\$ 0.25$. As soon as you have located the item, I would like you to say "Got it". Afterwards, I would like for you to return to the sign, which will be the starting position for each object."

"I would now like for you to locate a vendor that is selling a T-shirt for $\$ 1.46$. As soon as you locate the item, say "Got it", and then return to the starting position.

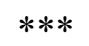


"We are ready to begin the experimental session. In just a second, I will read you some additional instructions, and then you will be given a series of target items one-by-one with either a picture of an item or a description of an item in addition to the price of the item. You will be allowed to look at the card for 30 seconds, and will then have to locate the item. Target items will have signs next to them with their price; do not pay attention or search for an item that does not have a sign next to it. There are several vendors selling similar items, but for different prices. You must locate the target item with the price noted on the card. As soon as you locate the item, say "Got it”, and return to the starting position. You will have two minutes to locate each item, and I will alert you if your time is up. I will be recording the time it takes to locate items, as well as additional information. You will always begin at the camel sign, and return to the sign after you locate an item. The time it takes to locate an item will only stop when you verbally acknowledge that you have located an item, so let me know as soon as you find it. Do you have any questions?" 
APPENDIX F

VIRTUAL MARKETPLACE EXAMPLES

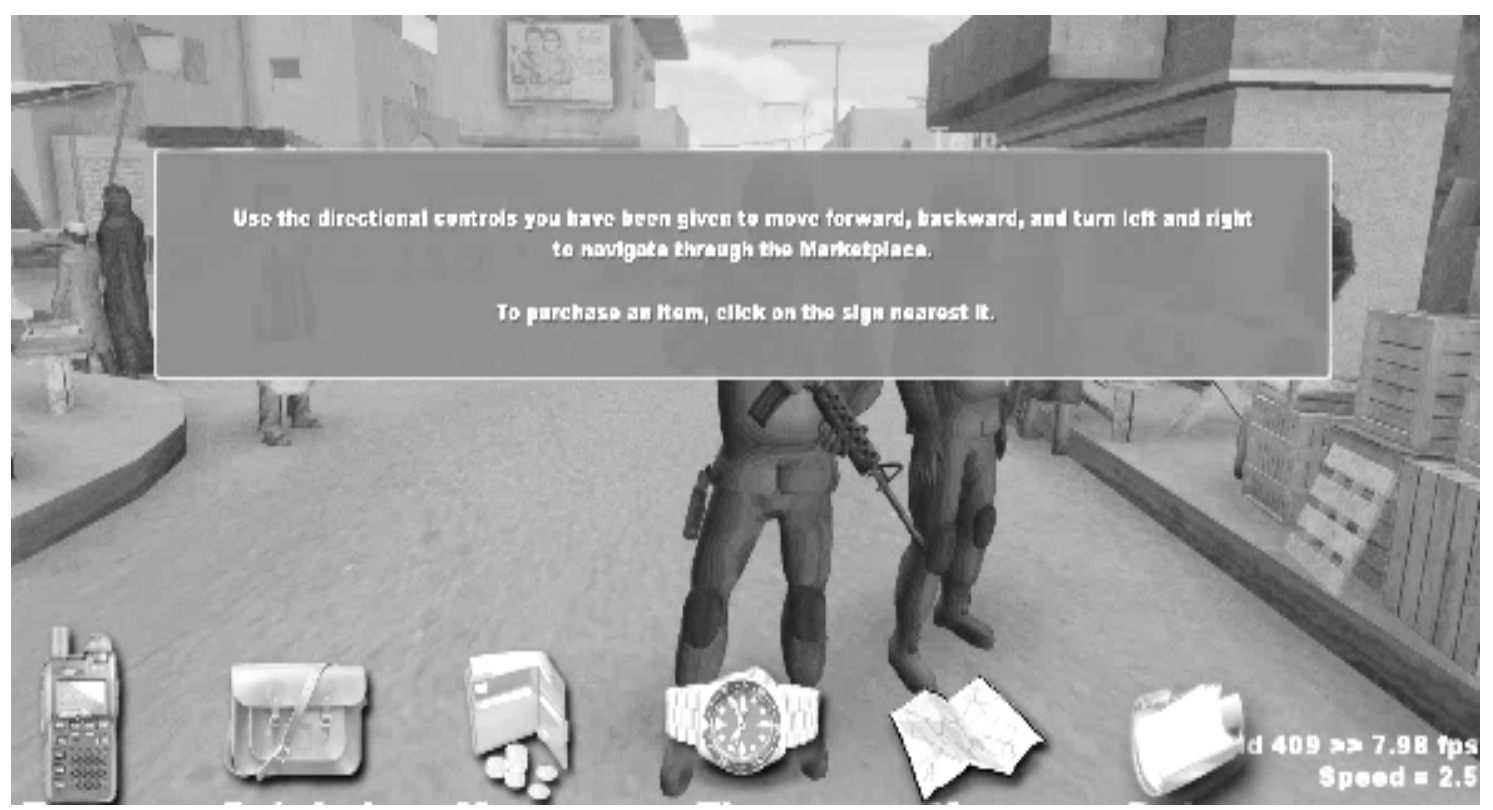

Initial navigation instructions (participants did not purchase items).

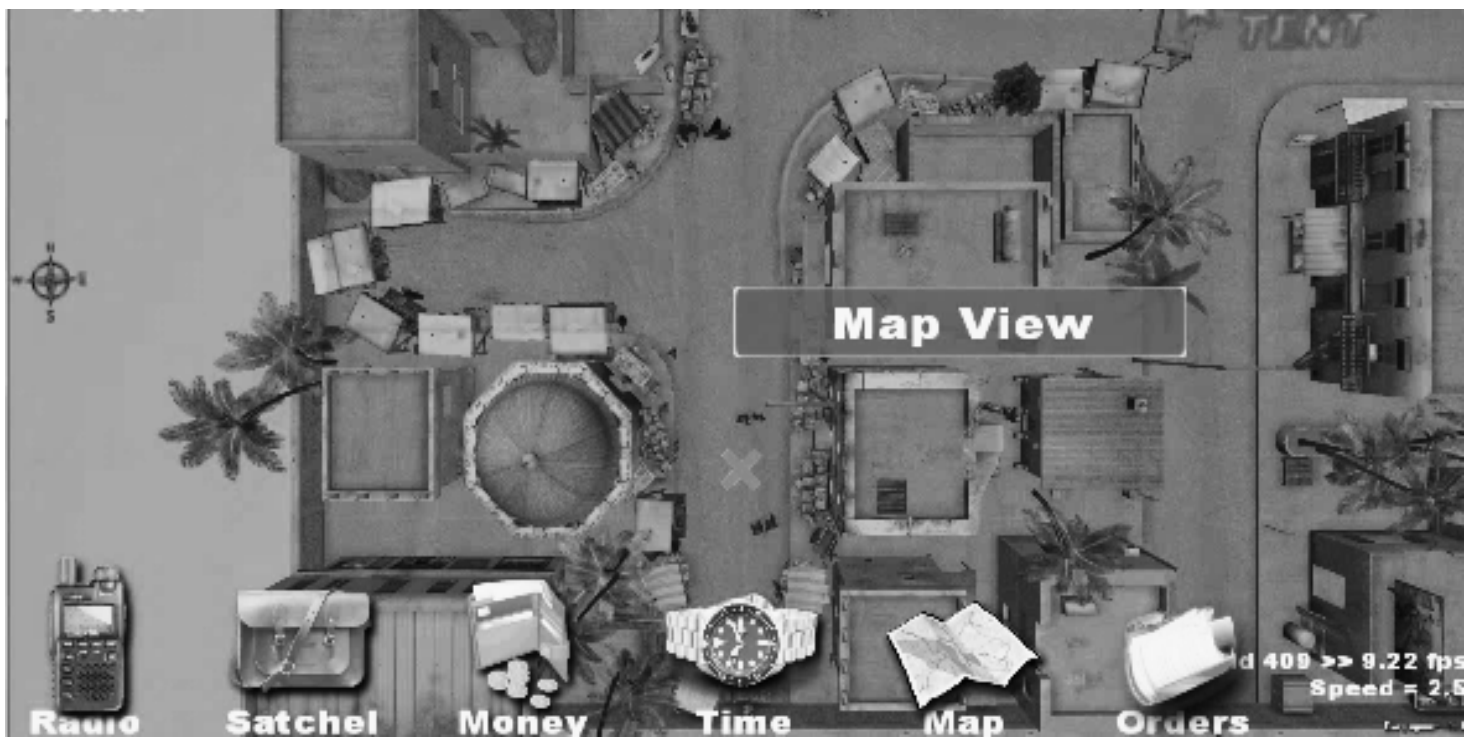

Starting position is marked by the " $\mathrm{X}$ " in the above screenshot. 


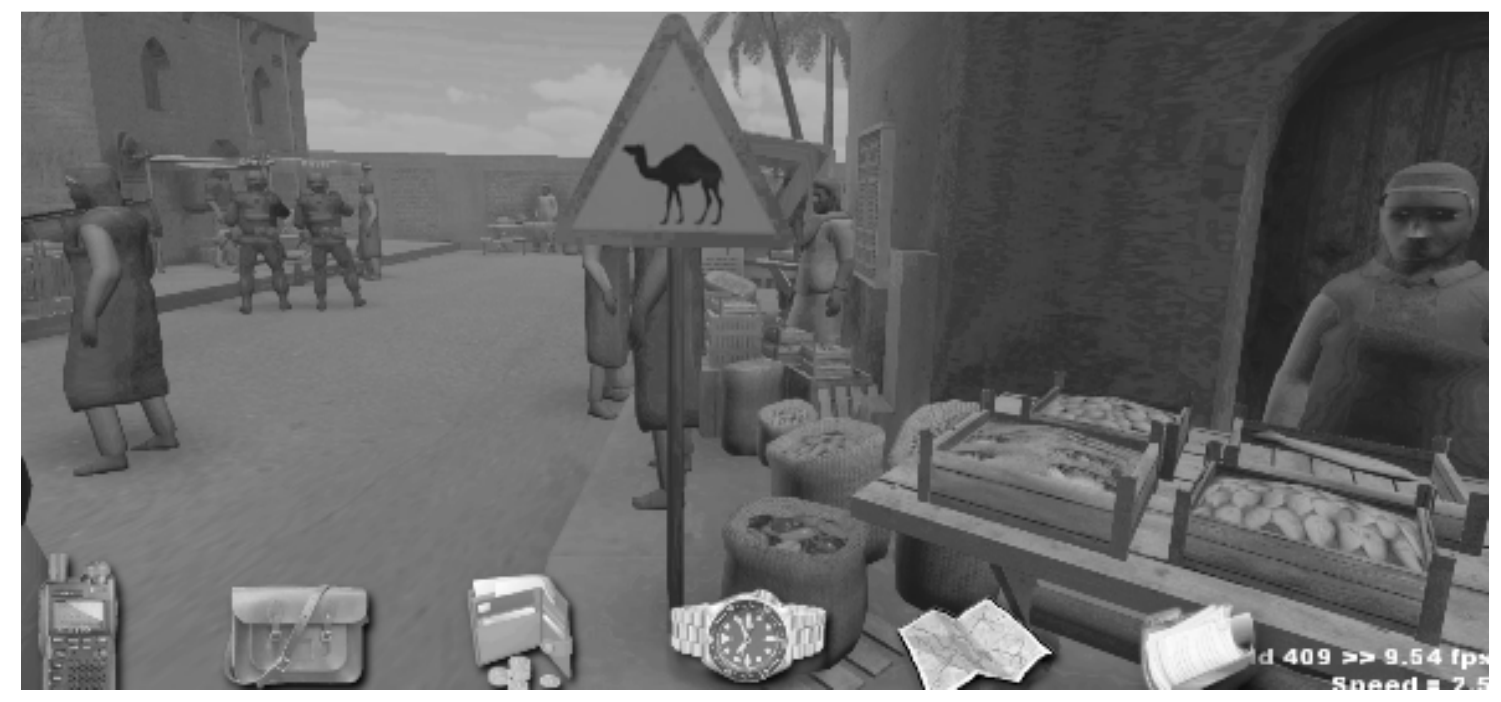

Participants were required to begin at this sign (marked by the " $\mathrm{X}$ " in the previous screenshot), and return to the sign once object was located.

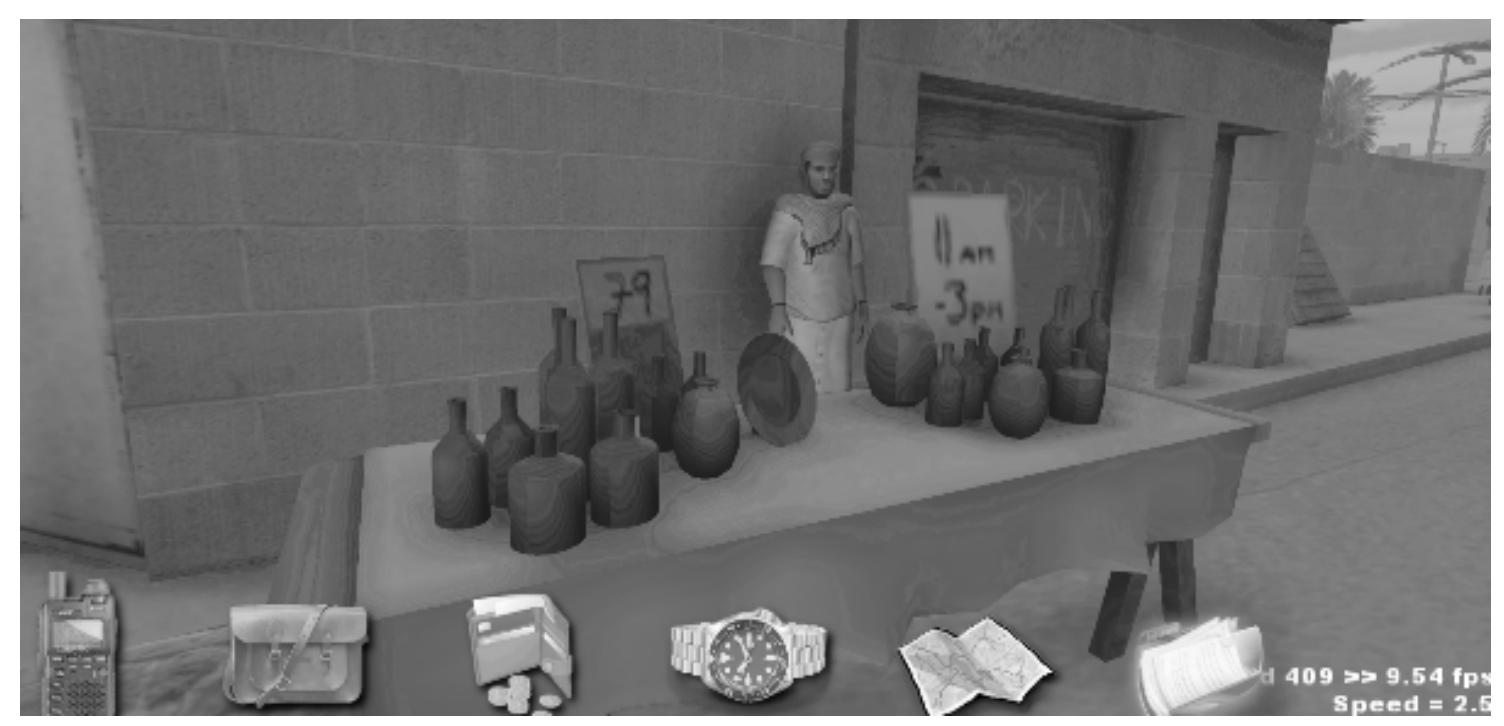

An example of a vendor in which a target was located. 

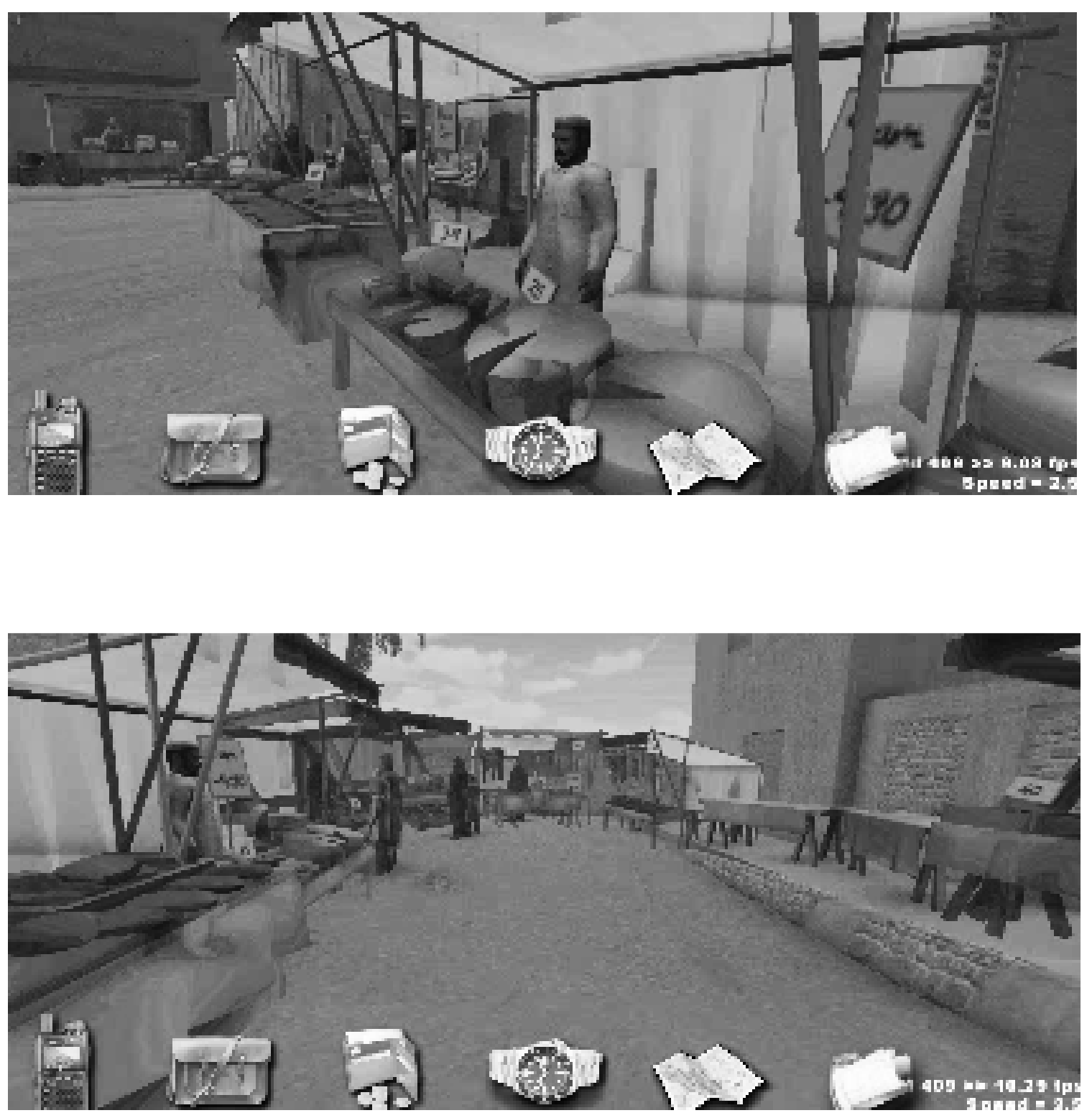

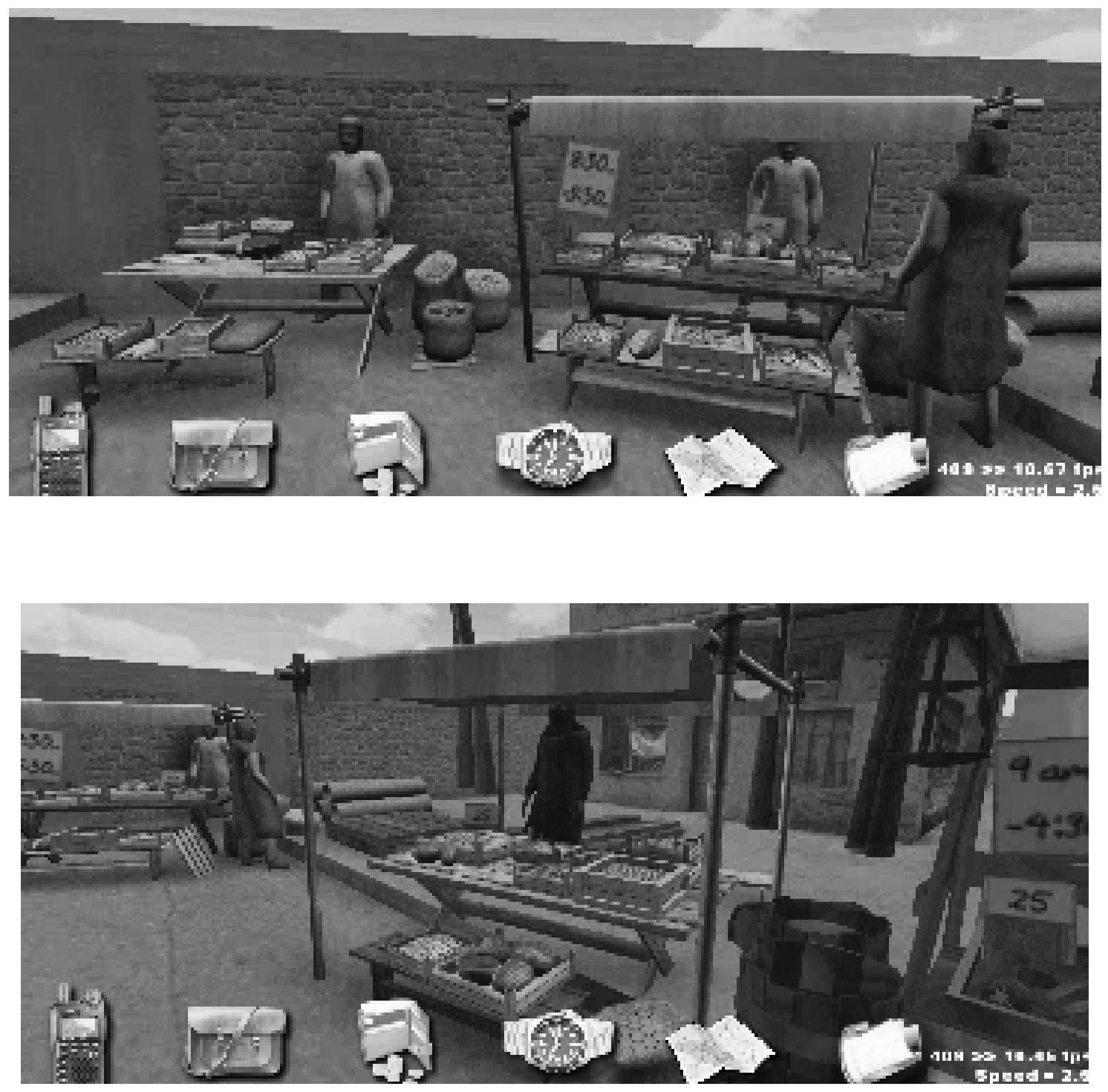

Additional marketplace screenshots. 


\section{APPENDIX G}

\section{OBJECTS}

$\underline{\text { Target as it appears in environment }}$

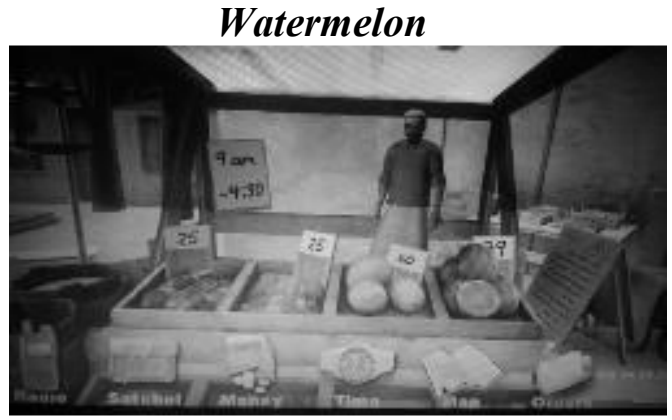

Peaches

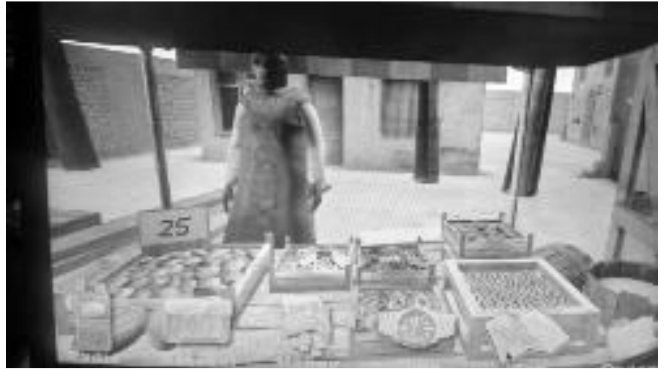

Lemons

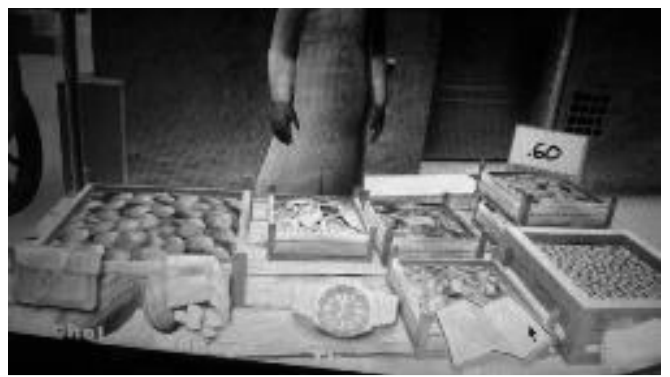

Belt

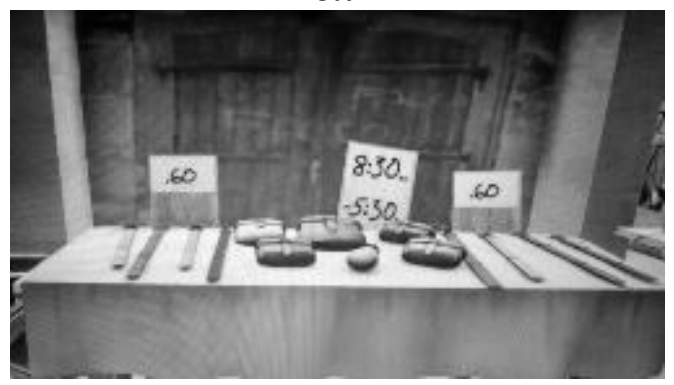

Description of item as it appears on card (either pictorial or lexical)

A large spereical oblong fruit that is popular in the American summer time. The exterior of the fruit is green and the interior is a dark pink/ red color. This fruit has black seeds and is native to southern Africa.

\section{The cost of this item is $\$ .079$}

A spherical fruit that is light orange in color. The skin of this fruit is fuzzy, and the fruit has a single large pit. This fruit is native to North-West China.

\section{The cost of this item is $\$ \mathbf{~} \mathbf{0 . 2 5}$}

An ellipsoidal yellow fruit that fits in the palm of your hand. The meat of this fruit is very sour and generally would not be eaten plain. This fruit is very popular for cooking, baking, and cocktails.

The cost of this item is $\$ \mathbf{\$ 0 . 6 0}$

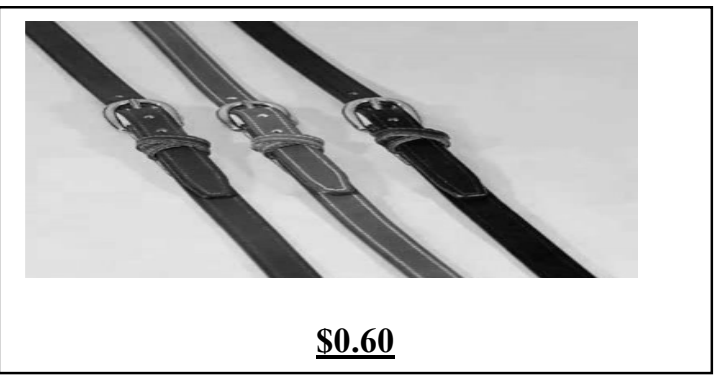



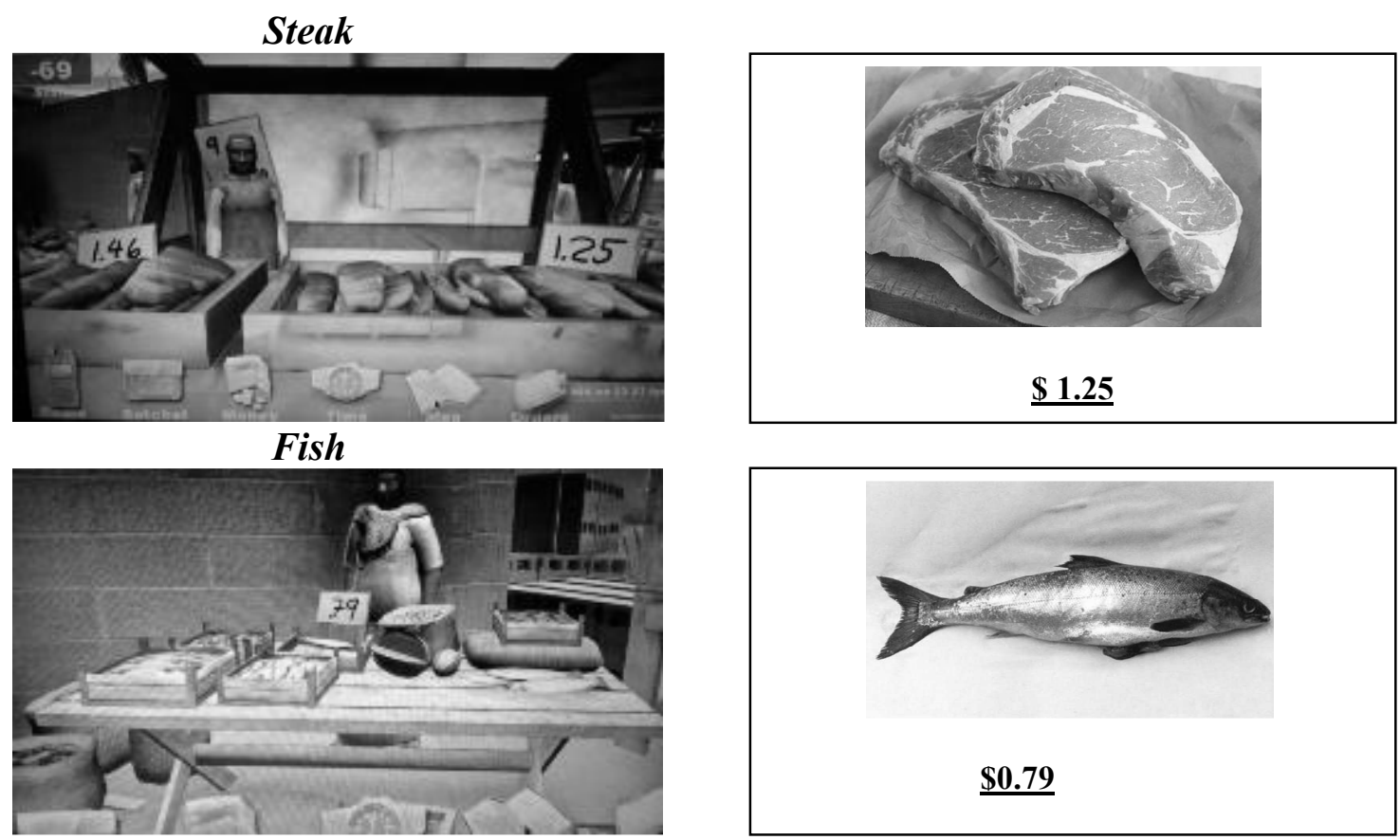

\section{Cup/Challice}
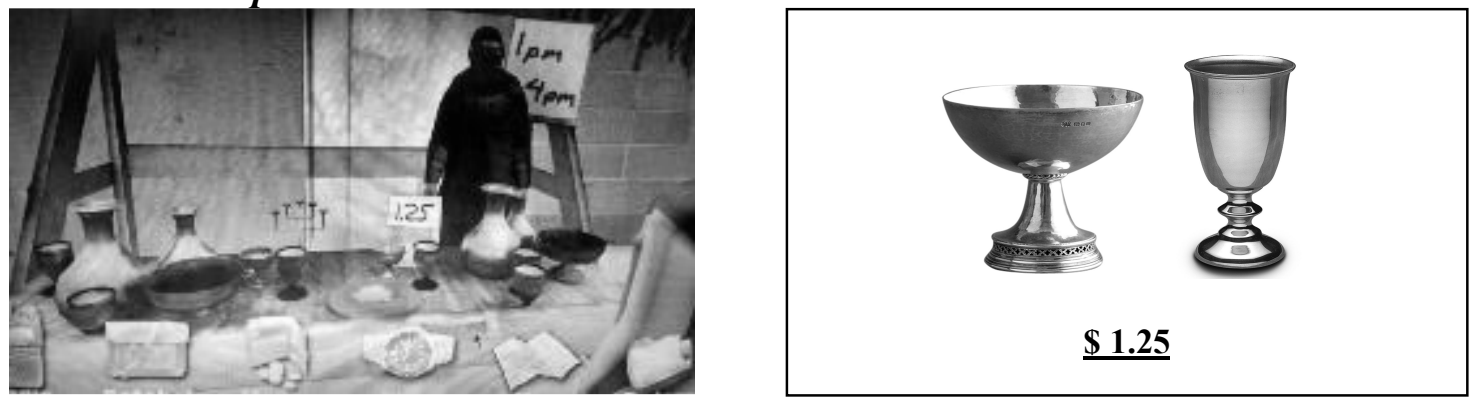

\section{Clay vase}
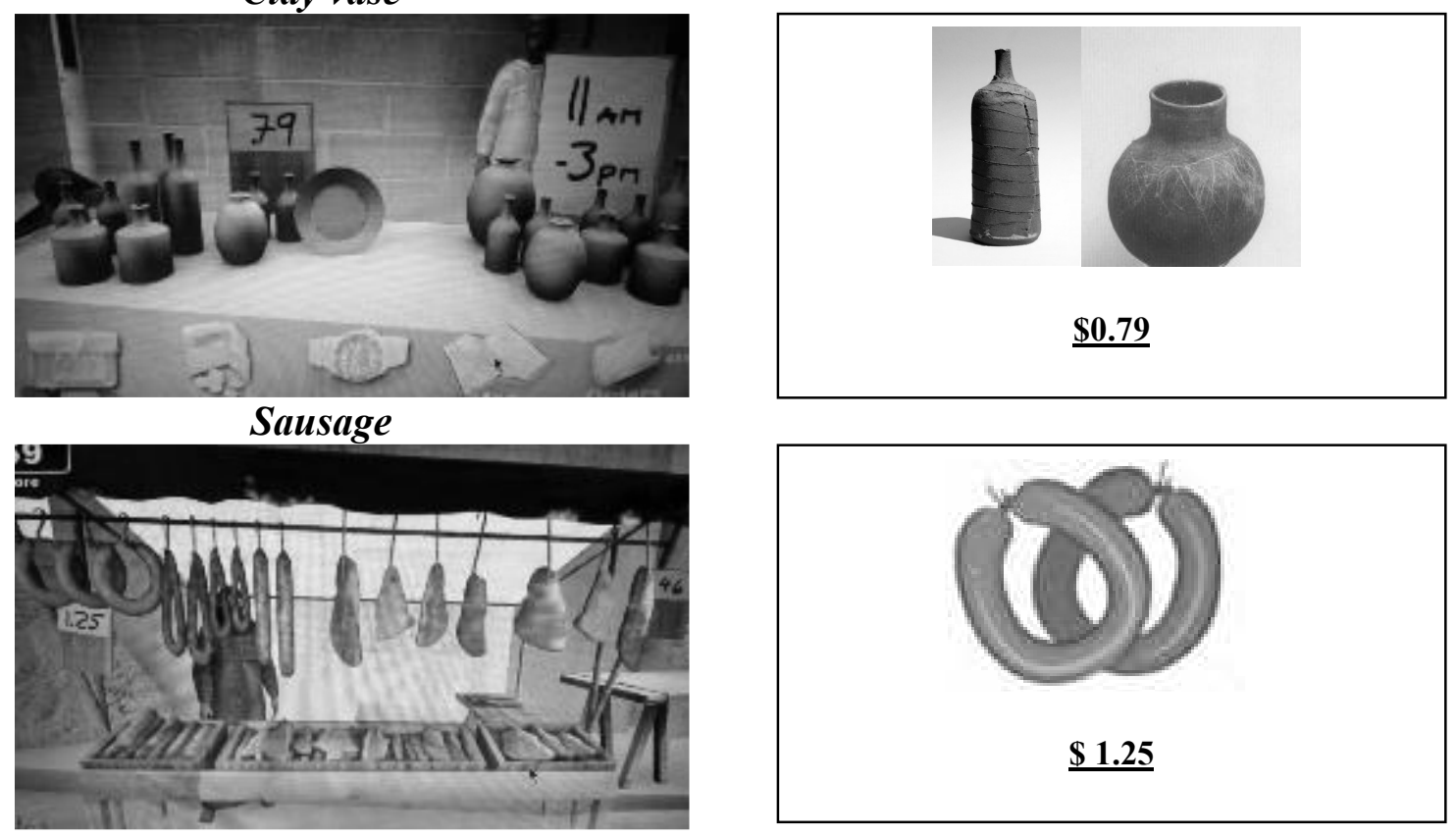


\section{Tunic}

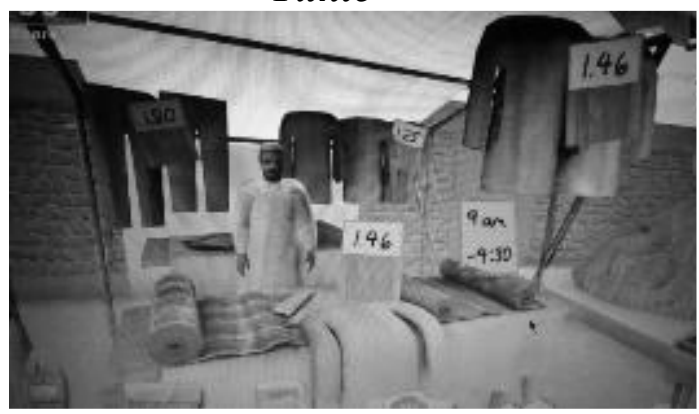

Pants

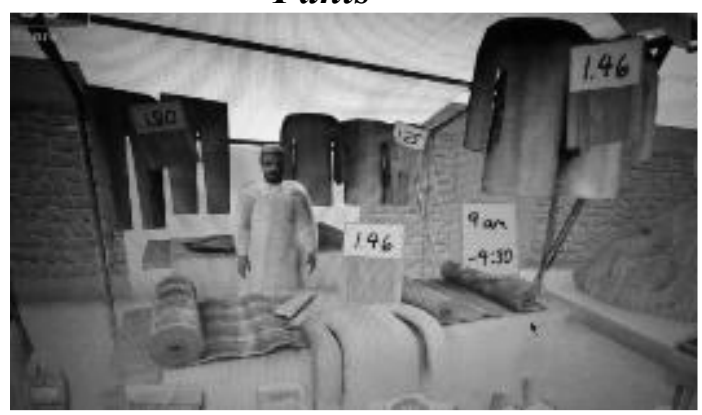

Honeydew Melon

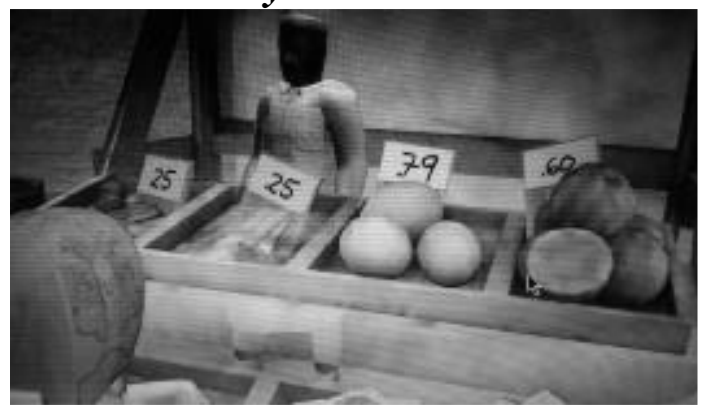

Oranges

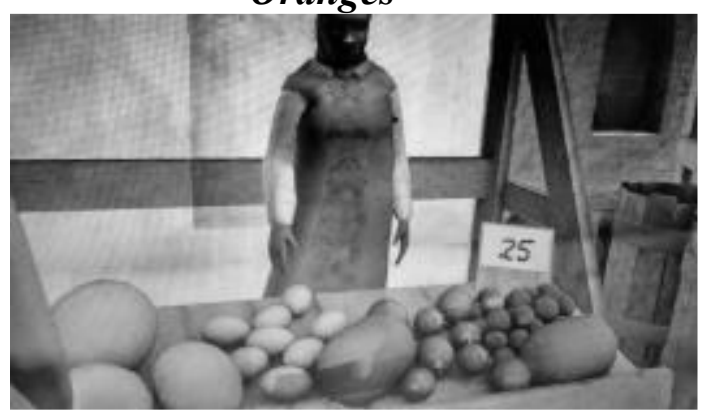

A simple garment worn and made by the local Middle-Eastern population. This garment is used to cover the torso. The color of this garment is white, and it originated in Ancient Rome.

\section{The cost of this item is $\$ 1.25$}

An item of clothing worn from the waste to the ankles. This garment separately covers both legs and is beige in color. This item of clothing has been worn since ancient times, and was historically borne only by men.

\section{The cost of this item is $\$ 1.80$}

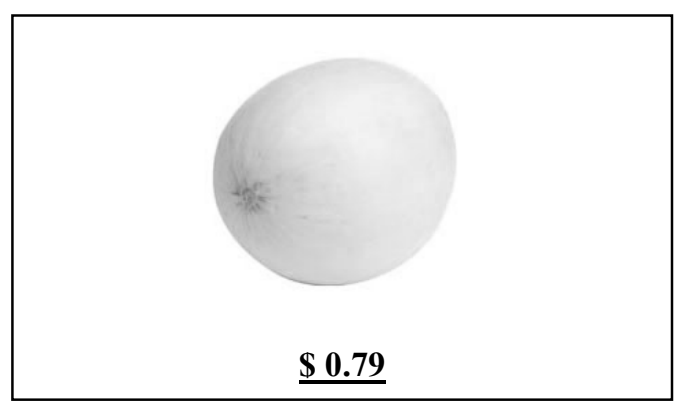

This citrus fruit is spherical and orange in color. It is historically a hybrid of a pomelo and mandarin, but has been widely cultivated and sold in America for hundreds of years. The meat of the fruit is sweet and its juice is often a popular breakfast beverage.

The cost of this item is $\$ 0.25$ 


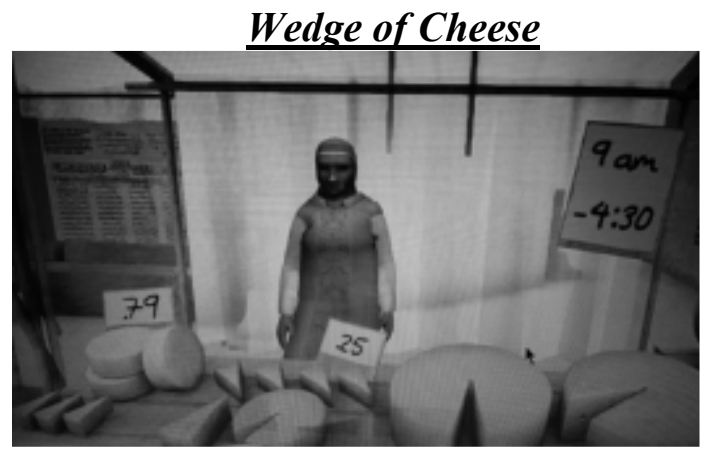

This dairy product is normally sold in slices but more expensive varieties are sold in wedges. This wedge-shaped item can be made from the milk of several different animals, but is normally made from the milk of cows.

The cost of this item is $\$ 0.25$

\section{Round of Cheese}
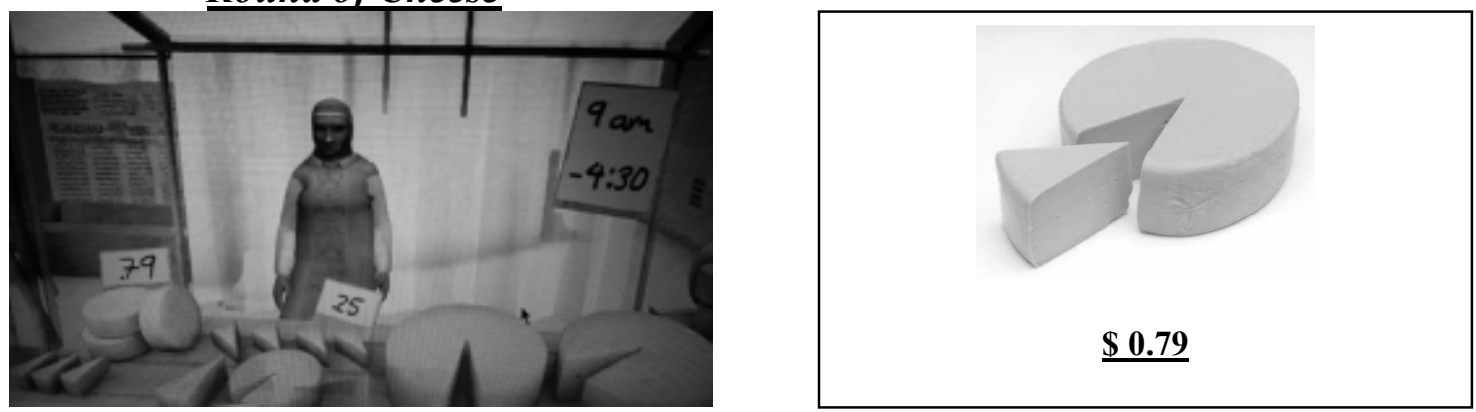

Round loaf of Bread

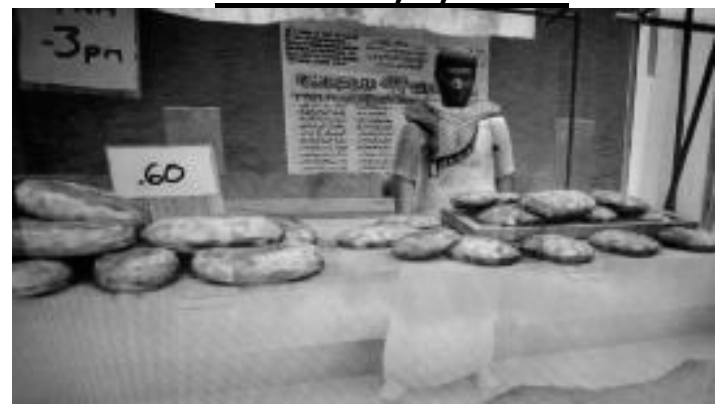

This food is typically prepared by baking dough made from flour and water. The flour can be made from all types of grains. This food is conventionally cut into slices to eat, but you are searching for the whole item.

The cost of this item is $\$ 0.60$ 


\title{
APPENDIX H \\ HIGH/ LOW CRITICALITY TASK INSTRUCTIONS
}

\author{
(Read by researcher at the beginning and midway through experimental task)
}

High criticality instructions (read to military): "You are a Sergeant in the Army. Your MOS is a combat medic; 68 Whiskey. You are working in a combat support hospital just outside of Baghdad. A couple of your buddies were just out on patrol and their HUM-V was hit with an IED. They were brought back inside the wire successfully, but your unit is running really low on supplies. The only MD, who happens to be the only Colonel, on the FOB sent you out to get some stuff, because your buddies aren't going to make it without some extra supplies. The stuff he told you to get is a little out there, but this is his fifth deployment successfully treating troops, and besides, he's the Colonel. If you don't get back to the FOB with this stuff IMMEDIATELY, your battle buddies might not make it. They were injured pretty badly and there's no more morphine in the CSH. Hurry up and find this stuff."

Radio call for high $\rightarrow$ low criticality (read to military): "Alright Doc, you just got a radio call and some supplies showed up just in time. Your buddies are stable now and they're going to pull through, but the Colonel still wants you to get the rest of the stuff. He said if you don't finish getting everything, you're going to have extra duty and he's not signing off on your battlefield promotion. Hurry up and finish so you can go check on your buddies".

Low criticality instructions (read to military): "You are a Sergeant in the Army. Your MOS is a combat medic; 68 Whiskey. You are working in a combat support hospital just outside of Baghdad. It is a slow day and the only MD (who happens to also be the only Colonel) on the FOB just told you to go down to the market and get some supplies. It is a list of strange things, but he said if you don't get everything on the list, you will have extra duty and he won't sign off on your battlefield promotion. Hurry up and get the supplies so you can get back and get some sleep."

Radio call for low $\rightarrow$ high criticality (read to military): "Doc, a radio call just came in and some of your buddies were hit with an IED while they were out on patrol. They were transported back to the FOB OK, but there are no supplies left at the CSH. Your buddies are fading fast and the Colonel said getting the rest of this stuff might be their only hope. Hurry up and get the rest of it so you can get back and help your battle buddies."

High criticality instructions (read to students): "You are a Sergeant in the Army. Your job is a combat medic. You are working in a combat support hospital just outside of Baghdad. A couple of your buddies were just out on patrol and their vehicle was hit with a road-side bomb. They were brought back to the base successfully, but your unit is running really low on supplies. The only doctor, who happens to be your boss and the Colonel, on the base sent you out to get some stuff, because your buddies aren't going to make it without some extra supplies. The stuff he told you to get is a little out there, but this is his fifth deployment successfully treating Soldiers, and besides, you always have to do what he says. If you don't get back to the base with this stuff IMMEDIATELY, your buddies might not make it. They were injured pretty badly and there's no more morphine in the hospital. Hurry up and find this stuff."

Radio call for high $\rightarrow$ low criticality (read to students): "Alright Sergeant, you just got a radio call and some supplies showed up just in time. Your buddies are stable now and they're going to pull through, but the Colonel still wants you to get the rest of the stuff. He said if you don't finish getting everything, you're going to have extra duty and he's not signing off on your promotion. Hurry up and finish so you can go check on your buddies".

Low criticality instructions (read to students): "You are a Sergeant in the Army. Your job is a combat medic. You are working in a combat support hospital just outside of Baghdad. It is a slow day and the only doctor (who happens to be your boss and the only Colonel) on the base just told you to go down to the market and get some supplies. It is a list of strange things, but he said if you don't get everything on the list, you will have extra duty and he won't sign off on your promotion. Hurry up and get the supplies so you can get back and get some sleep."

Radio call for low $\rightarrow$ high criticality (read to students): "Sergeant, a radio call just came in and some of your buddies were hit with a road-side bomb while they were out on patrol. They were transported back to the base OK, but there are no supplies left at the hospital. Your buddies are fading fast and the Colonel said getting the rest of this stuff might be their only hope. Hurry up and get the rest of it so you can get back and help your buddies." 


\section{APPENDIX I}

\section{ICONS/ DISPLAYS}

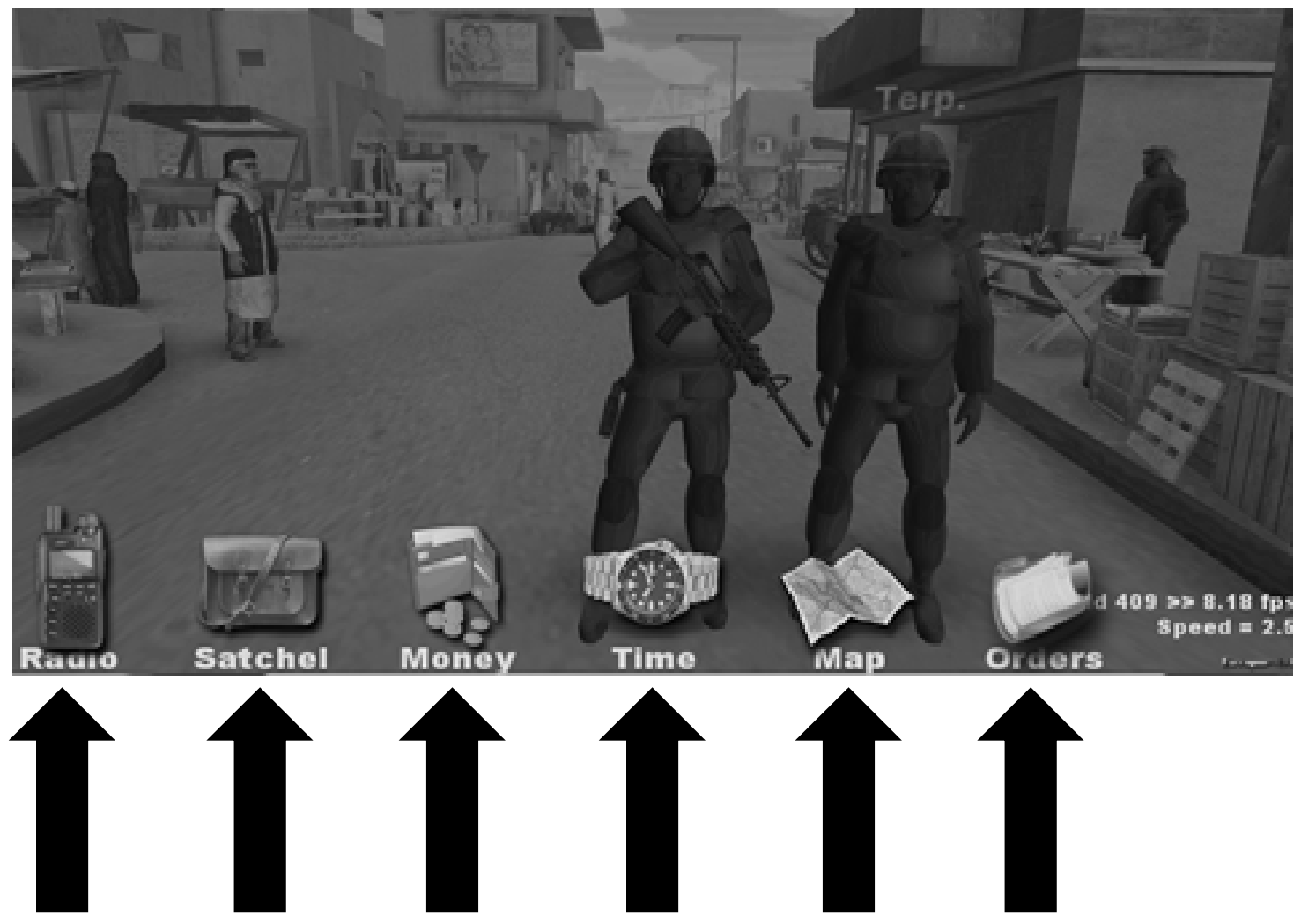

Icons/ additional displays are available within the scenario, but are considered errors if used by the participant. 


\section{VITA}

\section{Julie A. Hanson}

Department of Psychology

250 Mills Godwin Building

Old Dominion University

Norfolk, VA 23529 - 0267

\section{EDUCATION:}

(2012-2015) M.S.
639 Bosque Vista Pt.

Colorado Springs, CO 80916

Tel: (719) 313-2385

Email: jhans021@odu.edu

2012 B.S.

Old Dominion University, Norfolk, VA

Human Factors Psychology (In Progress)

Applied/ Experimental Psychology

Old Dominion University, Norfolk, VA

Major: Psychology

Minor: Political Science

\section{PROFESSIONAL EXPERIENCE:}

Fall 2014: User Experience Based Web Design at Alpha Cube Designs (Internship)

Supervisor: Dr. Pawan Vora

- Interactive web design using human factors and user experience (UX) methods. Assisted with developing wireframes and web pages using a variety of coding techniques.

- Experience with HTML 5, CSS, PHP, JavaScript, jQuery, Bootstrap, Adobe products

Summer 2014: Human Factors Intern (LARSS) at NASA Langley Research Center

Supervisor: Dr. Kara Latorella

- Project RADWORKS- Human subjects testing conducted to identify potential usability issues associated with constructing radiation shelters in zero gravity environments. Assisted with experimental design, human subjects testing, data coding, and data analyses to pinpoint usability/ safety concerns related to potential radiation exposure during long-duration space missions. Participated in a documentary film ("Stripping the Universe") detailing the project and shelter experiments.

TEACHING EXPERIENCE:

Fall 2013- Present: Graduate Teaching Assistant. Psychology Department, Old Dominion University. Course: PSYC 317 Quantitative Methods.

\section{INTERNSHIPS:}

Fall 2014 - Alpha Cube Designs (Denver, CO).

Summer 2014 - NASA LARSS (NASA/ Langley Research Center).

UNIVERSITY SERVICE:

Fall 2013- Summer 2014: Treasurer, Old Dominion University Human Factors and Ergonomics Society (HFES) Student Chapter.

\section{AFFILIATIONS:}

Human Factors and Ergonomics Society ODU Student Chapter

January 2012- Present

Human Factors and Ergonomics Society National Chapter

Golden Key Honor Society

January 2013- Present

January 2012- Present 